Portland State University

PDXScholar

\title{
Analysis of the Conformational Behavior and Stability of the SAP and TSAP Isomers of Lanthanide(III) NB-DOTA-Type Chelates
}

Gyula Tircso

University of Debrecen

Benjamin Charles Webber

Portland State University, benjamin_webber@hotmail.com

Benjamin E. Kucera

University of Minnesota

Victor G. Young

University of Minnesota

Mark Woods

Portland State University, mark.woods@pdx.edu

Follow this and additional works at: https://pdxscholar.library.pdx.edu/chem_fac

Part of the Chemistry Commons

Let us know how access to this document benefits you.

\section{Citation Details}

Published as: Tircso, G., Webber, B. C., Kucera, B. E., Young, V. G., \& Woods, M. (2011). Analysis of the conformational behavior and stability of the SAP and TSAP isomers of lanthanide(III) NB-DOTA-type chelates. Inorganic Chemistry, 50(17), 7966-7979.

This Post-Print is brought to you for free and open access. It has been accepted for inclusion in Chemistry Faculty Publications and Presentations by an authorized administrator of PDXScholar. Please contact us if we can make this document more accessible: pdxscholar@pdx.edu. 


\title{
Analysis of the Conformational Behavior and Stability of the SAP and TSAP Isomers of Lanthanide(III) NB-DOTA-Type Chelates
}

\author{
Gyula Tircso $^{\dagger}$, Benjamin C. Webber ${ }^{\ddagger}$, Benjamin E. Kucera§, Victor G. Young ${ }^{\S}$, and Mark \\ Woods $\ddagger$, $\|,{ }^{*}$ \\ tDepartment of Inorganic and Analytical Chemistry, University of Debrecen, P.O. Box 21, \\ Egyetem tér 1, Debrecen H-4010, Hungary \\ FDepartment of Chemistry, Portland State University, 1719 SW 10th Avenue, Portland, Oregon \\ 97201, United States \\ $\S$ Department of Chemistry, University of Minnesota, 207 Pleasant Street S.E., Minneapolis, \\ Minnesota 55455, United States
}

"Advanced Imaging Research Center, Oregon Health \& Science University, 3181 SW Sam Jackson Park Road, L485, Portland, Oregon 97239, United States

\begin{abstract}
Controlling the water exchange kinetics of macrocyclic $\mathrm{Gd}^{3+}$ chelates, a key parameter in the design of improved magnetic resonance imaging (MRI) contrast media, may be facilitated by selecting the coordination geometry of the chelate. The water exchange kinetics of the monocapped twisted square antiprism (TSAP) being much closer to optimal than those of the mono capped square antiprism (SAP) render the TSAP isomer more desirable for high relaxivity applications. Two systems have been developed that allow for selection of the TSAP coordination geometry in 1,4,7,10-tetraazacyclododecane-1,4,7,10-tetraacetic acid (DOTA)-type $\mathrm{Gd}^{3+}$ chelates, both based upon the macrocycle nitrobenzyl cyclen. In this paper we report investigations into the stability and formation of these chelates. Particular focus is given to the production of two regioisomeric chelates during the chelation reaction. These regioisomers are distinguished by having the nitrobenzyl substituent either on a corner or on the side of the macrocyclic ring. The origin of these two regioisomers appears to stem from a conformation of the ligand in solution in which it is hypothesized that pendant arms lie both above and below the plane of the macrocycle. The conformational changes that then result during the formation of the intermediate $\mathrm{H}_{2} \mathrm{GdL}^{+}$ chelate give rise to differing positions of the nitrobenzyl substituent depending upon from which face of the macrocycle the $\mathrm{Ln}^{3+}$ approaches the ligand.
\end{abstract}

(C) 2011 American Chemical Society

*Corresponding Author Phone: + 15037258238 or + 1503418 5530.mark.woods@pdx.edu or woodsmar@ohsu.edu. ASSOCIATED CONTENT

Supporting Information. Crystallographic data in CIF format. Further details are given in Figures S1-S6. This material is available free of charge via the Internet at http://pubs.acs.org. 


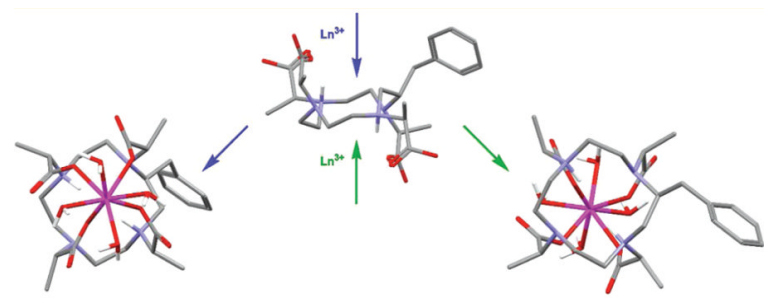

\section{INTRODUCTION}

Water exchange is one of several key parameters in the function of magnetic resonance imaging (MRI) contrast agents. The protons of water molecules coordinated to a paramagnetic metal ion are characterized by extremely short longitudinal relaxation time constants $\left(T_{1}\right)$. Exchange between these protons and those of the bulk solvent causes the $T_{1}$ of the bulk water to become shorter. Clearly the length of time that a water molecule resides upon the metal ion is crucial to this $T_{1}$-shortening effect; too short and the protons do not have sufficient time to be relaxed, too long and a relaxed water molecule needlessly occupies a coordination site on the metal ion. So controlling the water exchange rate of an MRI contrast agent, which generates increased image contrast through the shortening of tissue $T_{1}$ 's, is critical to improving its function.

The $\mathrm{Gd}^{3+}$ ion is the most commonly used paramagnetic ion in MRI contrast media because of its high spin state and long electron relaxation time. However, the water exchange kinetics of the $\mathrm{Gd}^{3+}$ chelates in clinical use as contrast agents are much slower than the optimal value determined by theory. ${ }^{1}$ This does not limit the efficacy (termed relaxivity) of these agents because their relaxivity is limited by rapid molecular reorientation, a result of their small size. However, in targeted imaging approaches envisioned for future molecular imaging applications the contrast agent must bind to a large biological target that would slow this molecular rotation. Under these circumstances suboptimal water exchange kinetics will limit relaxivity. It is therefore not surprising then that considerable effort has been directed to accelerating the water exchange kinetics of $\mathrm{Gd}^{3+}$ chelates. ${ }^{2-8}$ Our own efforts in this area ${ }^{6,7}$ have been very successful affording $\mathrm{Gd}^{3+}$ chelates that are optimal for maximizing relaxivity at $1.5 \mathrm{~T}$, currently the most common magnetic field strength used for clinical imaging studies.

The rationale behind our approach was to modify the solution state behavior of the popular MRI contrast agent GdDOTA (Dotarem). In solution GdDOTA exists as a mixture of two isomers, a monocapped square antiprism (SAP) and a monocapped twisted square antiprism (TSAP). These structures are in dynamic equilibrium in solution, interconverting by either ring flip or pendant arm rotation. ${ }^{9,10}$ The significance of this isomerism is that water exchange has been found to occur upward of an order of magnitude more rapidly in the TSAP isomer than in the SAP. ${ }^{11-13}$ However, in solution GdDOTA predominates as the SAP isomer ( $85 \%$ SAP). ${ }^{14}$ Thus, constraining a $\mathrm{Gd}^{3+}$ chelate to adopt solely a TSAP isomer would be desirable for development of contrast agents for targeted molecular imaging applications. Appropriately substituting both the macrocyclic ring and the pendant arms of a GdDOTA-type chelate, as in NB-DOTMA or 1 (Chart 1), can halt both these processes of isomer interconversion. ${ }^{6,7}$ Furthermore, by ensuring that the configuration of the chiral centers in both locations, ring and pendant arms, are the same one may "select" a ligand that will afford a chelate that is exclusively TSAP, that is, $S-S S S-\mathbf{1} .6,7$

In addition to more rapid water exchange kinetics that confer higher relaxivities upon $\mathrm{Gd}^{3+}$ chelates used as targeted MRI contrast agents, it is critical to also consider the stability of 
these chelates. A targeted contrast agent is expected to reside in the body much longer than a conventional agent; bound to its target it must not allow the central, and toxic, $\mathrm{Gd}^{3+}$ ion to be released until after the agent has been excreted from the body. The thermodynamic and kinetic stability of $\mathrm{Ln}^{3+}$ chelates of $S$-RRRR-NB-DOTMA and $S$-SSS-1, which will adopt exclusively SAP and TSAP isomers, respectively, are therefore of considerable interest. In this report we examine the thermodynamic stability, as well as conformational and kinetic aspects of the formation of these isomerically "selective" chelates.

\section{EXPERIMENTAL SECTION}

\section{General Remarks}

All solvents and reagents were purchased from commercial sources and used as received. HPLC purifications were performed on Water $\delta$-Prep 150 HPLC system using a Phenomenex Luna C-18 reversed-phase $(50 \times 250 \mathrm{~mm})$ column. LC-MS analysis was performed on a Thermo Scientific Accela pump with autosampler using a Thermo Scientific LTQ XL/LTQ Orbitrap Discovery. ${ }^{1} \mathrm{H}$ NMR spectra were recorded on a Varian Mercury, Bruker Avance IIa or Avance III spectrometer operating at 300.01, 400.13, or $600.13 \mathrm{MHz}$, respectively. ${ }^{13} \mathrm{C}$ NMR spectra were recorded on a Varian Mercury spectrometer operating 75.47 MHz. The syntheses of $S$-RRRR-NB-DOTMA-tetraethyl ester and $S$-SSS-1 have been described previously. ${ }^{7}$ A synthetic procedure for the preparation of DOTMA is provided in a companion paper. ${ }^{15}$

\section{$(1 R, 4 R, 7 R, 10 R)-\alpha, \alpha^{\prime}, \alpha^{\prime \prime}, \alpha^{\prime \prime \prime}-$ Tetramethyl-[(S)-2-(p-nitrobenzyl)]-1,4,7,10- tetraazacyclododecane-1,4,7,10-tetraacetic Acid (S-RRRR-NB-DOTMA)}

To a solution of $S$-RRRR-NB-DOTMA-tetraethyl ester $(0.20 \mathrm{~g}, 0.28 \mathrm{mmol})$ in tetrahydrofuran $(5 \mathrm{~mL})$ was added a $1.0 \mathrm{M}$ solution of sodium hydroxide $(1.13 \mathrm{~mL})$. Water $(4 \mathrm{~mL})$ was added to the reaction mixture which was then stirred at $50{ }^{\circ} \mathrm{C}$ for $18 \mathrm{~h}$. The solvents were removed under reduced pressure, and the residue taken up into water $(20 \mathrm{~mL})$. The resulting solution was filtered through a $0.45 \mu \mathrm{m}$ syringe filter prior to purification by preparative HPLC. Preparative HPLC purification was performed on a C-18 column using water $(0.037 \% \mathrm{HCl})$ as eluent for $5 \mathrm{~min}$ and then a linear gradient to $40 \% \mathrm{MeCN}$ and $60 \%$

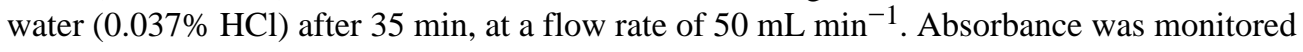
at 205 and $270 \mathrm{~nm}$. After removing the solvents by freeze-drying, the title compound was obtained as a colorless solid $(0.07 \mathrm{~g}, 38 \%)$.

HPLC $R_{\mathrm{T}}=28.15 \mathrm{~min} ; \mathrm{Mp}=193{ }^{\circ} \mathrm{C}$, decomposes; ${ }^{1} \mathrm{H}$ NMR $\left(400 \mathrm{MHz}, \mathrm{D}_{2} \mathrm{O}, \mathrm{pD} 3\right), \delta=$ $8.17\left(2 \mathrm{H}, \mathrm{s}\right.$ br Ar), $7.43\left(2 \mathrm{H}, \mathrm{d}\right.$ br, $\left.{ }^{3} J_{\mathrm{HH}}=8 \mathrm{~Hz}, \mathrm{Ar}\right), 4.12-2.74\left(21 \mathrm{H}, \mathrm{m} \mathrm{br},{ }^{3} J_{\mathrm{HH}}=8 \mathrm{~Hz}\right.$, $\mathrm{C}_{2} \mathrm{Ar}$, ring $\left.\mathrm{NCH}_{2}, \mathrm{NCH}\right), 1.63-1.26\left(12 \mathrm{H}, \mathrm{m} \mathrm{br}, \mathrm{CH}_{3}\right) ; \mathrm{m} / z$ (ESMS ESI-): 594 (100\%, $\left.\left[\mathrm{H}_{3} \mathrm{~L}\right]^{-}\right)$, Anal. Found $\mathrm{C}=45.8 \%, \mathrm{H}=6.9 \%, \mathrm{~N}=9.9 \%, \mathrm{C}_{27} \mathrm{H}_{41} \mathrm{~N}_{5} \mathrm{O}_{10} \bullet 2\left(\mathrm{H}_{2} \mathrm{O}\right) \bullet 2(\mathrm{HCl})$ requires $\mathrm{C}=46.0 \%, \mathrm{H}=6.7 \%, \mathrm{~N}=9.9 \%$.

Crystallography-A crystal (approximate dimensions $0.20 \times 0.10 \times 0.10 \mathrm{~mm}^{3}$ ) of $\mathrm{H}_{4}$ DOTMA $(\mathrm{HCl})_{2}\left(\mathrm{H}_{2} \mathrm{O}\right)_{3}$ was placed onto the tip of a $0.1 \mathrm{~mm}$ diameter glass capillary and mounted on a Bruker SMART Platform CCD diffractometer for a data collection at 173(2) $\mathrm{K} .{ }^{16}$ A preliminary set of cell constants was calculated from reflections harvested from three sets of 20 frames. These initial sets of frames were oriented such that orthogonal wedges of reciprocal space were surveyed. This produced initial orientation matrices determined from 58 reflections. The data collection was carried out using MoK $\alpha$ radiation (graphite monochromator) with a frame time of $60 \mathrm{~s}$ and a detector distance of $4.897 \mathrm{~cm}$. A randomly oriented region of reciprocal space was surveyed to the extent of one sphere and to a resolution of $0.84 \AA$. Four major sections of frames were collected with $0.30^{\circ}$ steps in $\omega$ at four different $\phi$ settings and a detector position of $-28^{\circ}$ in $2 \theta$. The intensity data were 
corrected for absorption and decay (SADABS). ${ }^{17}$ Final cell constants were calculated from the $x y z$ centroids of 2488 strong reflections from the actual data collection after integration (SAINT). ${ }^{18}$ Please refer to Table 4 for additional crystal and refinement information. The structure was solved using SHELXS-97 ${ }^{19}$ and refined using SHELXL-97. ${ }^{19}$ The space group $P 2{ }_{1} 22_{1}$ was determined based on systematic absences and intensity statistics. A direct-methods solution was calculated which provided most non-hydrogen atoms from the E-map. Full-matrix least-squares/difference Fourier cycles were performed which located the remaining non-hydrogen atoms. All non-hydrogen atoms were refined with anisotropic displacement parameters. The carboxylic acid and water protons were placed from the difference map and were refined with relative isotropic displacement parameters. The $\mathrm{O}-\mathrm{H}$ bond distances for the water protons were placed at $0.84 \AA$ Asing the HIMP instruction. All remaining hydrogen atoms were placed in ideal positions and refined as riding atoms with relative isotropic displacement parameters. The final full matrix least-squares refinement converged to $R 1=0.0441$ and $w R 2=0.1085\left(F^{2}\right.$, all data).

\section{Stability Determinations and Formation Kinetics}

Preparation and Standardization of Stock Solutions: Stock solutions of lanthanide chlorides $\left(\mathrm{Ln}^{3+}=\mathrm{Ce}^{3+}, \mathrm{Gd}^{3+}\right.$, and $\left.\mathrm{Yb}^{3+}\right)$ were prepared by dissolving the corresponding $\mathrm{Ln}_{2} \mathrm{O}_{3}$ in concentrated hydrochloric acid. Excess $\mathrm{HCl}$ acid was removed by repeated evaporation to dryness until dissolution of the residue in water afforded a solution with a $\mathrm{pH}$ in the range 4.5-5.5. The concentrations of the stock solutions so prepared were determined by complexometric titration using a standardized $\mathrm{Na}_{2} \mathrm{H}_{2}$ EDTA solution in the presence of xylenol orange as an indicator. The $\mathrm{Na}_{2} \mathrm{H}_{2}$ EDTA solution was standardized with $\mathrm{ZnCl}_{2}$ stock solution (prepared by dissolving metallic zinc $(99.9 \%$, Merck) in diluted $\mathrm{HCl}$ solution) using eriochrome black $\mathrm{T}$ as an indicator). Stock solutions of the ligands were prepared from solid samples of the ligand by dissolution in water and filtering through a $0.45 \mu \mathrm{M}$ membrane filter. The concentration of the ligand stock solutions were determined by potentiometric titration using a standardized $\mathrm{KOH}(0.1817 \mathrm{M})$ solution kept under $\mathrm{N}_{2}$, both in the absence and presence of a large excess of $\mathrm{Ca}^{2+}\left(\left[\mathrm{Ca}^{2+}\right] /[\mathrm{L}]\right.$ ratio was approximately 40). Prior to titration the $\mathrm{pH}$ of each ligand solution was set to about 1.75-1.80 by addition of a measured volume of strong acid $(\mathrm{HCl})$ of known concentration, facilitating measurements of the lowest protonation constants. In presence of $\mathrm{Ca}^{2+}$ all the acidic protons dissociate; thus the difference in base consumption in presence and absence of $\mathrm{Ca}^{2+}$ ion, which corresponds to two highly basic protons, located on amines of the macrocycle. The protonation constants of each ligand were calculated from the data obtained by titrating 1.8 and $2.6 \mathrm{mM}$ ligand samples with standardized $\mathrm{KOH}$ solution in the absence of $\mathrm{Ca}^{2+}$ over the $\mathrm{pH}$ range of 1.75-11.95.

Potentiometric Titrations: Potentimetric titrations were carried out with a Thermo Orion EA940 expandable ion analyzer using Thermo Orion semimicro combination electrode $8103 \mathrm{BN}$ in a thermostatted (at $25.0^{\circ} \mathrm{C}$ ) vessel. A Metrohm DOSIMATE 665 autoburet (5 $\mathrm{mL}$ capacity) was used for base additions (of volumes not less than $0.005 \mathrm{~mL}$ ) and $1.0 \mathrm{M}$ $\mathrm{KCl}$ was used to maintain the ionic strength. The protonation constant determinations were carried out in $8.00 \mathrm{~mL}$ sample volumes with magnetic stirring, and during the titrations, argon gas was passed over the top of the samples to maintain a $\mathrm{CO}_{2}$-free environment. Standard buffers (Borax: $0.01 \mathrm{M}, \mathrm{pH}=9.180$ and $\mathrm{KH}$-phthalate $0.05 \mathrm{M}, \mathrm{pH}=4.005$ ) were used to calibrate the electrode. The titrant, a carbonate-free $\mathrm{KOH}$ solution, was standardized against $0.05 \mathrm{M} \mathrm{KH}$-phthalate solution by $\mathrm{pH}$-potentiometric method. The method proposed by Irving et al. was used ${ }^{20}$ to obtain $\mathrm{H}^{+}$ion concentrations from the measured $\mathrm{pH}$ values; therefore, "stoichiometric" constants were determined. The ionic product, $\mathrm{p} K_{\mathrm{w}}$ of water was also calculated for an acid-base titration and was found to be 13.754 . 
Owing to the slow rates of chelation involving $\mathrm{Ln}^{3+}$ ions and $1,4,7,10$ -

tetraazacyclododecane-1,4,7,10-tetraacetic acid (DOTA)-type ligands, the stability constants of the chelates were determined using the "out-of-cell" technique (also known as the batch method). Sixteen $1.5 \mathrm{~mL}$ samples of known ligand and $\mathrm{Ln}^{3+}$ ion concentrations (approximately $2 \mathrm{mM}$ each by applying slight $1.5-2 \%$ ligand excess) were prepared, and the total acid concentration in the samples was varied. The $\mathrm{pH}$ of the samples was adjusted to a range within which chelation was expected to take place, the $\mathrm{pH}$ range was approximated by equilibrium calculations with the use of stability data published for LnNB-DOTA complexes. ${ }^{21}$ Each sample was then sealed under a blanket of $\mathrm{N}_{2}$ and kept in an incubator at $40{ }^{\circ} \mathrm{C}$ for 2 months and then at $25^{\circ} \mathrm{C}$ for a further 3 months. The minimum time required to reach equilibrium was established by preliminary relaxometric studies using the most acidic and basic samples prepared for the $\mathrm{Gd}^{3+}$ chelates in duplicates which were kept together with the rest of the "out-of-cell" samples. When equilibrium had been established the samples were opened and the equilibrium $\mathrm{pH}$ measured. PSEQUAD software ${ }^{22}$ was then used to process the titration data, calculating the protonation and stability constants using eqs 1 and 2. For each $\mathrm{Ln}^{3+}$ system the Irving factor was determined before and after the $\mathrm{pH}$ measurement of the samples had occurred. The average of these values was used to correct the measured $\mathrm{pH}$ readings for differences caused primarily by the diffusion potential.

$$
\begin{gathered}
K_{i}^{\mathrm{H}}=\frac{\left[\mathrm{H}_{i} \mathrm{~L}\right]}{\left[\mathrm{H}_{i-1} \mathrm{~L}\right]\left[\mathrm{H}^{+}\right]} \\
K_{\mathrm{ML}}=\frac{[\mathrm{ML}]}{[\mathrm{M}][\mathrm{L}]}
\end{gathered}
$$

Kinetics of Formation: Because of the relatively high stability of the intermediates $\mathrm{H}_{2} \mathrm{GdL}^{+}$obtained by direct $\mathrm{pH}$-potentiometric titrations, the chelate formation was studied for mixtures with 10 -fold ligand excess $\left(1.00 \mathrm{mM} \mathrm{Gd}^{3+}\right.$ and $10.0 \mathrm{mM}$ ligand). Under these conditions the saturation value of the formation rate constant is likely to be obtained $\left(k_{\text {obs }}\right.$ $\left(\mathrm{s}^{-1}\right)=k_{\mathrm{r}}\left(\mathrm{s}^{-1}\right)$ ). This was confirmed for acidic samples experimentally (for which the conditional stability is the lowest) by varying the ligand concentration in the concentration range of $4.0 \mathrm{mM}$ to $13.6 \mathrm{mM}(\mathrm{pH} 5.16$ (S-RRRR-NB-DOTMA and $S$-SSS-1) and $\mathrm{pH} 4.37$ and 4.67 (NB-DOTA). The pseudo-first-order rate constants ( $\left.k_{\mathrm{obs}}\right)$ obtained in the given concentration range were identical to the uncertainty of the measurements (the reproducibility of $k_{\mathrm{obs}}$ was found to be in the range of 3-6\%, as determined at low and high $\mathrm{pH}$ values for the GdNB-DOTA). The formation rates of the $\mathrm{Gd}^{3+}$ chelates were studied by following the changes in $1 / T_{1}$ of the chelates over the course of the formation reaction. Longitudinal relaxation times were measured using the "inversion-recovery" pulse sequence $\left(180^{\circ}-\tau-90^{\circ}\right)$ using 6-8 different $\tau$ values on an MRS-6 NMR analyzer (Institut "Josef Stefan", Ljubljana, Slovenija), operating at $20 \mathrm{MHz}$. The sample temperature was maintained at $25^{\circ} \mathrm{C}$ with circulated air. Relaxometric data recorded as a function of time were fitted to eq 3 to evaluate the first-order rate constants with Scientist (Micromath) software using a standard least-squares procedure.

$$
R_{\mathrm{t}}=R_{\mathrm{e}}+\left(R_{0}-R_{\mathrm{e}}\right) \cdot \mathrm{e}^{(-k \cdot t)}
$$

where the $R_{0}, R_{\mathrm{e}}$, and $R_{\mathrm{t}}$ are the longitudinal relaxation rates measured at the start of the reaction $(t=0)$, at equilibrium condition, and at time $t$, respectively) 
Regioisomeric Dependence upon Reaction Conditions-A single stereoisomer of $S$-RRRR-NB-DOTMA was obtained by preparative RP-HPLC. Stock solutions of ligand $(56.4 \mathrm{mM})$ and $\mathrm{YbCl}_{3}(170.3 \mathrm{mM})$ were prepared in water. A series of $1.0 \mathrm{M}$ buffers $\left(\mathrm{KHSO}_{4} / \mathrm{HOAc}, \mathrm{pH} 3.5\right), \mathrm{NaOAc} / \mathrm{HOAc}, \mathrm{pH} 4.0,4.5,5.0$ ), (MES, pH 5.5, 6.0) were prepared, and the $\mathrm{pH}$ of each was adjusted at $60{ }^{\circ} \mathrm{C}$. Each buffer and stock solution was equilibrated at $60{ }^{\circ} \mathrm{C}$ prior to use. Each buffer was used to prepare a sample $7.1 \mathrm{mM}$ in ligand, $14.2 \mathrm{mM}$ in $\mathrm{YbCl}_{3}$, and with a total volume of $500 \mu \mathrm{L}$. Each sample was then sealed in a vial and incubated at $70{ }^{\circ} \mathrm{C}$ for 64 days. A second stock solution of $\mathrm{YbCl}_{3}$ was prepared in $1.0 \mathrm{M} \mathrm{NaOAc} / \mathrm{HOAc}$ buffer at $\mathrm{pH} 5.0(170.3 \mathrm{mM})$. This solution was used to prepare samples of different concentration but at a fixed ligand/ $\mathrm{YbCl}_{3}$ ratio (1:2) in $1.0 \mathrm{M} \mathrm{NaOAc/}$ HOAc buffer at $\mathrm{pH}$ 5.0. Solutions at $[S-R R R R$-NB-DOTMA] $=0.5,1.0,2.5,5.0,10,25$, and $50 \mathrm{mM}$ were prepared, also sealed in a vial, and incubated for 64 days at $70{ }^{\circ} \mathrm{C}$.

The samples were allowed to cool to room temperature for $24 \mathrm{~h}$ prior to analysis. The ratio of regioisomeric products in each vial was determined by LC-MS. Each sample was diluted to a concentration of $50 \mu \mathrm{M}$ using 1:1 Methanol/Water. Each sample was then injected in a $250 \times 2.0 \mathrm{~mm}$ Phenomenex luna C18(2) eluting with a linear gradient from $100 \%$ water $\left(0.05 \%\right.$ formic acid) to $80 \%$ acetonitrile after $35 \mathrm{~min}$, with a flow rate of $375 \mu \mathrm{L} \mathrm{min}{ }^{-1}$. The entire eluent flowed directly to an ESI-MS detector monitoring for $\mathrm{m} / \mathrm{z}=765$ in negative ionization mode. The distribution of isomers was determined by manual integration of the area of the peaks in the chromatogram. After LC-MS analysis all samples were combined and purified by prep RP-HPLC. ${ }^{1} \mathrm{H}$ NMR analysis of each fraction was used to ensure that the peaks were assigned to the correct regioisomer.

Epimerization Studies-A sample of YbS-SSS-1, purified by preparative RP-HPLC, was hydrogen-deuterium exchanged by repeated $\mathrm{D}_{2} \mathrm{O}$ addition/freeze-drying cycles. After $\mathrm{H} / \mathrm{D}$ exchange the sample was dissolved in $\mathrm{D}_{2} \mathrm{O}(\mathrm{pD} 1 \mathrm{DCl})(0.5 \mathrm{~mL})$ such that the chelate concentration was $20 \mathrm{mM}$. The sample was placed in a sealable $5 \mathrm{~mm}$ NMR tube, and the tube sealed. A ${ }^{1} \mathrm{H}$ NMR spectrum was recorded, and the sample incubated in an oil bath at $90{ }^{\circ} \mathrm{C}$. ${ }^{1} \mathrm{H}$ NMR scans were acquired initially at 1 week intervals, followed by $2-3$ week intervals later in the study. The ratio of regioisomers present in the study was determined by integrating all three methyl resonances of each regioisomer. After completion of the experiment, the sample was broken open, the solution removed from the NMR tube, and a portion was analyzed by ESI-MS to confirm the product mass $(\mathrm{m} / \mathrm{z}=751)$.

\section{RESULTS AND DISCUSSION}

\section{Isomerism During Chelate Formation}

We recently reported that the synthesis of $\mathrm{Ln}^{3+}$ chelates of NB-DOTMA ligands was complicated by the appearance of more than one reaction product. ${ }^{7}$ Two principal reaction products were observed and these had been attributed to racemization during the alkylation of the amine in the 1-position of the macrocycle. Thus, the two reaction products were attributed to the RRRR- and SRRR- (SAP), and SSSS- and RSSS- (TSAP) isomers. It is now clear that this rationalization is erroneous. The racemization explanation was based primarily upon the observation that the 1-position of the macrocycle is a much poorer nucleophile than the amines in other positions of the macrocycle. Indeed it is such a poor nucleophile that even in the presence of 4 equiv of a triflate as alkylating agent at room temperature it is possible to selectively alkylate the other three amines of the macrocycle, leaving the 1-position unreacted. ${ }^{7}$ This opened up the possibility of introducing an achiral pendant arm in the 1-position eliminating the perceived problem of racemization while maintaining the structural integrity of the coordination geometry. In initial experiments this approach appeared to be successful, affording $>90 \%$ of a single isomeric chelate. 
The synthesis of the tetra-ester of S-SSSS-NB-DOTMA afforded two compounds, present in roughly equal amounts, which could be distinguished by ${ }^{1} \mathrm{H}$ NMR after the alkylation reaction. Separation of these two compounds proved an intractable problem, and mass spectrometry showed that they had the same mass. The ligand was taken through to the corresponding $\mathrm{Eu}^{3+}$ chelate, and two chelates, both in the expected TSAP geometry, were observed by ${ }^{1} \mathrm{H}$ NMR and HPLC. The assignment to two diastereoisomers (differing in their configuration in the 1-position) seemed a reasonable one, particularly once a similar observation had been made for the chelates, but not the esters, of $S$-RRRR-NB-DOTMA. This reliance upon assessing the $\mathrm{Ln}^{3+}$ chelate rather than the ligand proves to have been the major error in these studies. There is a definite advantage to studying chelates of $\mathrm{Ln}^{3+}$ ions that induced large hyperfine shifts; the ${ }^{1} \mathrm{H}$ NMR of asymmetric ligands such as those studied here overlap with one another making structural determinations very difficult, introducing a shifting $\mathrm{Ln}^{3+}$ ion spreads these resonances out over a wide frequency window allowing better resolution of the chelate resonances. However, such an approach overlooks one key aspect of the formation of chelates with nitrobenzyl substituted DOTA-type ligands: an aspect that never became apparent during studies on the parent NB-DOTA chelates. ${ }^{21}$

In all known stable $\mathrm{Ln}^{3+}$ chelates of DOTA-type ligands the macrocyclic ring adopts a [3333] ring conformation. ${ }^{23}$ This places each amine on one of the side of a "square" ring and gives rise to two distinct carbon environments: a carbon may be either on the side or on the corner (Figure 1). Introducing a single substituent onto this ring, the ring will orient itself so as to place the substituent into an equatorial position, thus minimizing torsional strain. In the case of NB-cyclen the configuration of the chiral carbon is $S$-, and a $\delta \delta \delta \delta$ ring conformation will place the substituent into an equatorial position. This is the basis upon which the ring conformation is locked ${ }^{23}$ and the coordination geometry selected. ${ }^{6,7}$ However, what was not considered in detail previously is that for cyclen in a $\delta \delta \delta \delta$ conformation the equatorial protons on both the carbons on the corner and the side are pro-S. This means that a substituent can occupy one of two chemically distinct positions while adopting an equatorial position and locking the ring into a $\delta \delta \delta \delta$ conformation (Figure 1). Thus, for any singly substituted cyclen there are two possible regioisomeric structures, which may be identified from COSY NMR data. ${ }^{24}$

In the case of NB-DOTA, chelates of all the $\mathrm{Ln}^{3+}$ ions were prepared and analyzed by ${ }^{1} \mathrm{H}$ NMR. In each case only two structurally distinct chelates were identified corresponding to one SAP $\left(\Lambda(\delta \delta \delta \delta)\right.$ isomer and one TSAP $\left(\Delta(\delta \delta \delta \delta)\right.$ isomer. ${ }^{21}$ These two isomers were found to interconvert by arm rotation and in all cases where 2D-COSY data were acquired the nitrobenzyl substitutent was found to lie on a carbon at a corner. ${ }^{21}$ No sign of additional structures relating to regioisomerism of the nitrobenzyl substituent were observed in any of the NB-DOTA chelates. The first indication of regioisomerism arose during a study of the NIR-CD properties of YbNB-DOTMA chelates. ${ }^{24}$ As part of this study $2 \mathrm{D}-{ }^{1} \mathrm{H}$ NMR experiments were run on the chelates including a sample that had initially been assigned as the $S$-SRRR-isomer (Figure 2). This study placed the nitrobenzyl substituent on a carbon on the corner for the two chelates for which studies were completed (one SAP and one TSAP), but for the "S-SRRR-" isomer the nitrobenzyl substituent was found to lie on a carbon on the side of the ring. Appropriate weight was not given to the implication of this observation at the time. It was not until experiments looking at the stability of the chelates and the relative stability of each isomer were undertaken that the significance of this observation became clear.

\section{Protonation Constants}

The suitability of a $\mathrm{Gd}^{3+}$ chelate for in vivo application is in large part determined by its thermodynamic stability. This may conveniently be achieved by means of potentiometric titration. ${ }^{25}$ The first stage of this process being to determine the protonation constants of the 
ligand, information which may also shine light into other aspects of the ligand's behavior. The protonation constants of $S$-RRRR-NB-DOTMA and $S$-SSS-1 were determined by potentiometric titration using $1.0 \mathrm{M} \mathrm{KCl}$ as an ionic background. Each ligand exhibited five protonation constants, cf. the parent ligand DOTA (Table 1). However, an unusual phenomenon was observed in the case of $S$-SSS-1. Like the protonation constants for DOTMA, ${ }^{15}$ the fourth protonation constant of $S$-SSS-1 is actually higher than that of the third. This phenomenon has been noted previously in other aza-crown systems such as cyclam. ${ }^{26}$ In contrast, the third and fourth protonation constants of $S$-RRRR-NB-DOTMA follow the more normal incremental ordering also observed for DOTA. ${ }^{27}$

Although noted in other ligand systems, it is highly unusual for a protonation constant to be higher than the one that precedes it. One explanation for this unusal phenomenon is that one protonation step, in this case the third one, leads to a conformational change in the ligand. In this new conformation the site of the fourth protonation is rendered more basic than that same site in the initial conformation. If this change in basicity is large enough then the next protonation step, in this case the fourth one, may have a protonation constant that is higher than the previous one. One might expect that such situations are more likely to occur in highly rigid structures such as S-SSS-1 and DOTMA in which conformational exchange processes are likely to be restricted. In the case of $S-S S S-1$ this observation lead us to consider the possibility that one of the two conformations places the nitrobenzyl substituent on the side of the macrocyclic ring, and the other places it on the corner (Figure 1). At first glance it may also seem that this would account for the observation of regioisomeric products when $\mathrm{Ln}^{3+}$ chelates of $S-S S S-1$ are prepared. However, such an explanation does not really provide a satisfactory explanation to this question, nor does it account for conformational changes in DOTMA that also exhibits a fourth $\mathrm{p} K_{\mathrm{a}}$ that is higher than its third. ${ }^{15}$

As part of this study the $\mathrm{p} K_{\mathrm{a}}$ values of NB-DOTA were measured again, this time using 1.0 $\mathrm{M} \mathrm{KCl}$ as the ionic background. The reasons for choosing $\mathrm{KCl}$ as the ionic background have been expressed elsewhere, ${ }^{28}$ and while it offers certain advantages it must be borne in mind that the $\mathrm{K}^{+}$ion is not inert in these systems. Comparing the protonation data obtained for $\mathrm{NB}$-DOTA in $\mathrm{KCl}$ with that obtained in the more inert $\mathrm{Me}_{4} \mathrm{NCl}$ used initially, presents a more likely explanation for why some fourth $\mathrm{p} K_{\mathrm{a}}$ 's are higher than the third. The fourth $\mathrm{p} K_{\mathrm{a}}$ of NB-DOTA in $\mathrm{KCl}$ is also higher than the third, but this is not the case with $\mathrm{Me}_{4} \mathrm{NCl}$. It is known that the $\mathrm{K}^{+}$ion interacts, although weakly, with these types of amino carboxylate ligands. ${ }^{29}$ Thus, it seems likely that when $\mathrm{K}^{+}$is present in the system it interacts with the carboxylates of the ligand during the first two protonation steps which correspond to protonation of the macrocycle. This interaction makes it more difficult to protonate the carboxylates, thereby lowering the third $\mathrm{p} K_{\mathrm{a}}$. But addition of that third proton displaces $\mathrm{K}^{+}$ from the ligand altogether which renders the fourth protonation step more favorable, in certain cases more favorable than the third. Such a scenario is impossible with $\mathrm{Me}_{4} \mathrm{NCl}$ which cannot interact with the ligand and so in this case the $\mathrm{p} K_{\mathrm{a}}$ 's are observed to increase incrementally. Thus, an alternative explanation for the production of multiple regioisomeric chelates must be sought.

\section{Chelate Formation}

To probe why specific chelates are formed it is first necessary to understand the mechanism by which the chelates form. For $\mathrm{Ln}^{3+}$ chelates of DOTA this mechanism was elucidated by Brücher and co-workers. ${ }^{30}$ In this model the $\mathrm{Ln}^{3+}$ ion approaches the DOTA ligand and rapidly forms a weak intermediate chelate. Formation of this intermediate chelate results in the rapid dissociation of protons from all the ligand carboxylates and displacement of at least four water molecules from the inner hydration sphere of the metal ion. This intermediate chelate is primarily electrostatic in nature. The metal ion is bound through 
interactions with all four negatively charged carboxylate groups, and the macrocyclic ring remains diprotonated (the first and second $\mathrm{p} K_{\mathrm{a}}$ of DOTA correspond to trans-protonation of the macrocycle), such that this intermediate has been identified to be of the type $\mathrm{H}_{2} \mathrm{LnL}^{+} .30$ These two protons on the macrocyclic amines must then dissociate from the intermediate $\mathrm{H}_{2} \mathrm{LnL}^{+}$chelate in the rate determining step before the $\mathrm{Ln}^{3+}$ ion is able to drop down into the coordination cage of the ligand. The nature of the $\mathrm{H}_{2} \mathrm{LnL}^{+}$intermediate has recently been confirmed by potentiometric, luminescence, and EXAFS methods, although it has also has been shown that over time a second intermediate complex may form in which fewer water molecules are bound to the $\operatorname{Ln}^{3+}$ ion $(q=3) .^{31}$

Potentiometric titration of a ligand in the presence of $\mathrm{Gd}^{3+}$ allows the formation and in particular the stability of this intermediate chelate to be probed. Because the formation of the fully formed chelate is very slow, requiring the use of out-of-cell potentiometric techniques for measurement vide supra, these data are uncontaminated by subsequent formation of the fully formed chelate. The potentiometric titrations of S-RRRR-NB-DOTMA, S-SSS-1 as well as NB-DOTA in the presence and absence of $\mathrm{Gd}^{3+}$ (Supporting Information) reveal that all three ligands form the same $\mathrm{H}_{2} \mathrm{GdL}^{+}$type intermediate chelate on the way to the fully formed $\mathrm{Gd}^{3+}$ chelate. These titration data enable the stability constants of these intermediate chelates to be determined (Table 2). No notable trend is immediately apparent from these obtained values. However, the formation of $\mathrm{H}_{2} \mathrm{GdL}^{+}$intermediates for all the ligands under study here (and also for DOTMA) ${ }^{15}$ is an important observation from the point of view of the regiochemistry of the final chelates of $S$-RRRR-NB-DOTMA and S-SSS-1. It strongly indicates that the regiochemistry of the final chelate is determined in this fast initial step of the chelation mechanism since it is difficult, if not impossible, to understand how the $\mathrm{H}_{2} \mathrm{GdL}^{+}$chelate could undergo rearrangement so as to alter the position of a conformationally locked macrocyclic ring. Even though the mechanism by which the two trans- macrocyclic protons are removed remains the subject of some conjecture, ${ }^{30}$ neither proposed mechanism would facilitate the repositioning of the nitrobenzyl substituent. It seems more probable that the conformation of the ligand in solution and the direction of approach of the $\mathrm{Ln}^{3+}$ ion during the rapid first reaction step are the determining factors in the regiochemistry of the final chelate.

Furthermore, the data in Table 1 and 2 allow the mole fraction of $\mathrm{Gd}^{3+}$ to be calculated as a function of $\mathrm{pH}$ (Figure 3) for each ligand. This is important from the point of view of determination of the kinetics of formation of the fully formed chelates. Since the rate determining step is the transformation $\mathrm{H}_{2} \mathrm{GdL}^{+} \rightarrow \mathrm{GdL}^{-}+2 \mathrm{H}^{+}$, if accurate kinetic data are to be obtained it is critical that all experiments be performed under conditions that ensure $\mathrm{H}_{2} \mathrm{GdL}^{+}$is the sole species in solution in the initial stages of reaction (formation of $\mathrm{H}_{2} \mathrm{GdL}^{+}$ is so rapid as to be considered instantaneous for the purposes of these measurements). From Figure 3 it is clearly seen that above $\sim \mathrm{pH} 4.2$ all the ligands under investigation herein are exclusively in the form $\mathrm{H}_{2} \mathrm{GdL}^{+}$. Accordingly the kinetics measurements were made by measuring the decrease in $\mathrm{Gd}^{3+}$ relaxivity upon complex formation at different $\mathrm{pH}$ values in the range 5.16-7.12. Reactions were run in the presence of 5-14-fold excesses of ligand such that reactions were pseudo-first-order and described by eq 4 , where $[\mathrm{Gd}]_{\mathrm{t}}$ is the total concentration of $\mathrm{Gd}^{3+}$ and $k_{\mathrm{obs}}$ the pseudo-first-order rate constant.

$$
\frac{\mathrm{d}[\mathrm{GdL}]}{\mathrm{d} t}=k_{\mathrm{obs}}[\mathrm{Gd}]_{\mathrm{t}}
$$

The relationship between pseudo-first-order rate constants $k_{\mathrm{obs}}$ and ligand concentration is expressed by eq 5 ; in which $k_{\mathrm{f}}$ is the rate constant characterizing the rearrangement of 
$\mathrm{H}_{2} \mathrm{GdL}^{+}$into $\mathrm{GdL}^{-}+2 \mathrm{H}^{+}$and the $K^{\mathrm{C}} \mathrm{H} 2 \mathrm{~L}$ is the conditional stability constant of the $\mathrm{H}_{2} \mathrm{GdL}^{+}$.

$$
k_{\mathrm{obs}}=\frac{k_{\mathrm{f}} K_{\mathrm{H}_{2} \mathrm{GaL}^{+}}^{\mathrm{C}}[\mathrm{L}]}{1+K_{\mathrm{H}_{2} \mathrm{GdL}_{+}^{+}}^{C}[\mathrm{~L}]}
$$

Under conditions involving higher ligand concentrations, such as those employed here, $K_{\mathrm{H} 2 \mathrm{~L}}^{\mathrm{C}}[\mathrm{L}] \gg 1$, and thus $k_{\mathrm{obs}} \approx k_{\mathrm{f}}$. In other words $k_{\mathrm{f}}$ dominates the value of the pseudo-firstorder rate constant, $k_{\mathrm{obs}}$, when formation of the intermediate, $\mathrm{H}_{2} \mathrm{GdL}^{+}$, in the initial stages of the reaction is complete. $k_{\mathrm{f}}$ maybe further refined into the rate constants for water and base assisted deprotonation of the $\mathrm{H}_{2} \mathrm{GdL}^{+}, k_{\mathrm{H}_{2} \mathrm{O}}$ and $k_{\mathrm{OH}^{-}}$, respectively, according to eq 6 .

$$
k_{\mathrm{f}}=k_{\mathrm{H}_{2} \mathrm{O}}+k_{\mathrm{OH}^{-}}\left[\mathrm{OH}^{-}\right]
$$

Accordingly the experimentally determined values of the pseudo-first-order rate constant, $k_{\text {obs }}$ (that approximates to $k_{\mathrm{f}}$ ) were plotted against the concentration of hydroxide to afford values of $k_{\mathrm{H}_{2} \mathrm{O}}$ and $k_{\mathrm{OH}^{-}}$(Supporting Information). In each case the value of $k_{\mathrm{H}_{2} \mathrm{O}}$ was found to be small (Table 3 ) indicating that the contribution of water to deprotonation and rearrangement of $\mathrm{H}_{2} \mathrm{GdL}^{+}$into $\mathrm{GdL}^{-}$is negligible and the rate of chelate formation is essentially determined by $k_{\mathrm{OH}^{-}}{ }^{-}$(Table 3 ).

When the values of $k_{\mathrm{OH}^{-}}$determined for GdS-SSS-1 and GdS-RRRR-NB-DOTMA are compared with those obtained for the more flexible ligand systems GdNB-DOTA and EuDOTA $^{33}$ it is apparent that chelates of more substituted and therefore more rigid ligand systems form more slowly than those of more flexible ligand systems. It is noteworthy that NB-DOTA, which has a more rigid macrocyclic ring system than DOTA, forms chelates only marginally more slowly than DOTA but DOTMA, in which the rigidity of the ligand system is introduced into the pendant arms, exhibits a value of $k_{\mathrm{OH}^{-}}$(for the $\mathrm{Eu}^{3+}$ ion) that is 3 orders of magnitude smaller than DOTA. ${ }^{33}$ Indeed, all three of the chelates substituted in the $\alpha$-position of the pendant arms exhibit substantially slower kinetics of formation. One may conclude therefore that a significant change in pendant arm conformation is required to allow the $\mathrm{Ln}^{3+}$ ion to drop down into the coordination cage and that $\alpha$-substitution hinders these conformational changes.

The values of $k_{\mathrm{H}_{2} \mathrm{O}}$ and $k_{\mathrm{OH}^{-}}$determined here for $S$-SSS-1 and $S$-RRRR-NB-DOTMA are a weighted average of the values for both regioisomers of each chelate (side and corner). Other than identifying the key intermediate(s), the formation of which seems to give rise to different regioisomers, these data afford little information that can illuminate the question of why two regioisomeric chelates are produced for these chelates. To further probe this question a sample of $\mathrm{H}_{6} S$-RRRR-DOTMA was prepared and purified to a single isomer by prep-HPLC. This sample was then used to probe the effect of $\mathrm{pH}$ and concentration upon the regioisomeric ratio produced by preparing the corresponding $\mathrm{Yb}^{3+}$ chelate. $7.1 \mathrm{mM} S$ $R R R R$-DOTMA were prepared in $1 \mathrm{M}$ buffer solutions from $\mathrm{pH} 3$ to 6,2 equiv of $\mathrm{YbCl}_{3}$ were then added. Additional samples were prepared in $1.0 \mathrm{M} \mathrm{NaOAc}$ buffer at concentrations from 0.5 to $50 \mathrm{mM}$ in ligand, again with 2 equiv of $\mathrm{YbCl}_{3}$. All solutions were sealed in vials and incubated for 64 days at $70^{\circ} \mathrm{C}$, and the proportion of each regioisomer produced in each reaction was determined by LC-MS monitoring at $\mathrm{m} / \mathrm{z}=765$. Figure 4 shows that in all cases two chelates are produced; the ratio of these chelates is notable for not only its $\mathrm{pH}$ dependence but also its concentration dependence. 
The production of two isomeric chelates from a single stereoisomer of ligand unambiguously demonstrates that our earlier hypothesis (that the two chelates were the product of racemization during the alkylation reaction) was erroneous. The two chelates must instead differentiate themselves during chelate formation, and almost certainly during the initial formation of the $\mathrm{H}_{2} \mathrm{LnL}^{+}$intermediate chelate, vide infra. A sudden break in the regioisomerism of the chelates as a function of $\mathrm{pH}$ is not observed, consistent with the idea that $\mathrm{pH}$ dependent conformational changes are not responsible for the production of different regioisomers. The more gradual changes observed for the regioisomeric ratio with changing $\mathrm{pH}$ is suggestive of subtle changes in the relative rates of formation (and possibly also the reverse reactions) of each regiosiomer with changing $\mathrm{pH}$. However, care should be taken not to draw more detailed conclusions, even in a qualitative sense, from this data. The model of all equilibria involved in these processes is extremely complex, with many more quantities unknown than are known. It is unclear which if any samples have reached equilibrium. The choice of ligand/metal ratio was arbitrary and not designed to afford quantitative kinetic data. The use of $\mathrm{Na}^{+}$and $\mathrm{AcO}^{-}$in several buffers means that labile buffer components were employed in concentrations that are very high relative to the reactants. Nonetheless, these experiments also prove how it might have been possible to mistakenly believe that substitution of an achiral arm into the 1-position had solved the problem of multiple isomers. ${ }^{7}$ In that case the chelation reaction was performed at $\mathrm{pH} 5.5$ at $210 \mathrm{mM}$. From the data in Figure $4 \mathrm{~b}$ it is clear that as the concentration of reactants is increased, so increases the proportion of chelate with the substituent on the corner. Although this increase is modest at low concentrations, from 0.5 to $1 \mathrm{mM}$, as the concentration increases beyond $10^{-2} \mathrm{M}$ this increase becomes much more rapid. Extrapolating to $210 \mathrm{mM}$ it is very possible that only minimal quantities of a regioisomer with the substituent on the side would have been produced in that reaction.

\section{Conformational Analysis}

The ligand DOTMA represents a convenient starting point for an analysis of the conformational effects of regioisomerism of the nitrobenzyl substituent. In our hands nitrobenzyl substituted chelates, such as those of NB-DOTA, NB-DOTMA, and 1, do not crystallize but crash out of solution as amorphous solids. In contrast DOTMA crystallizes readily both as its hydrochloride or alkali metal salt. However, since chelation reactions are necessarily run under acidic conditions $\left(\mathrm{Ln}^{3+}\right.$ ions are poorly soluble at higher $\left.\mathrm{pH}\right)$, it is the protonated form of DOTMA that is more applicable as the starting point of studies into ligand conformation. X-ray quality crystals of $\mathrm{H}_{4}$ DOTMA $\bullet 2 \mathrm{HCl} \bullet 3 \mathrm{H}_{2} \mathrm{O}$ were grown from $\sim 5 \mathrm{M} \mathrm{HCl}$ by slow evaporation at $\sim 40^{\circ} \mathrm{C}$. The structure obtained from these crystals (Figure 5 and Table 4) shows the preorganized nature of this ligand system that confers extremely high thermodynamic stability upon its $\mathrm{Ln}^{3+}$ chelates. ${ }^{25}$ Although they crystallize in different space groups the structure of $\mathrm{H}_{4} \mathrm{DOTMA} \cdot 2 \mathrm{HCl}\left(P 2_{1} 2_{1} 2_{1}\right)$ is highly reminiscent of that determined for $\mathrm{H}_{4} \mathrm{DOTA} \bullet 2 \mathrm{HCl}\left(P 2_{1} / n\right)$ (Figure 6). ${ }^{11}$ In each structure the aza-crown adopts a [3333] conformation ${ }^{23}$ that confers the same helicity upon each ethylene bridge (Table 5). This [3333] ring conformation is notably more distorted in the structure of $\mathrm{H}_{6}$ DOTMA, which is diagonally elongated, than it is in $\mathrm{H}_{6}$ DOTA rendering each ethylene bridge in $\mathrm{H}_{6}$ DOTMA entirely nonequivalent to all the others. This conformation places all four pendant arms in each ligand structure on the same side of the macrocycle. In each structure the pendant arms are twisted into a slight helix that leads each ligand to resemble the structure observed in TSAP chelates rather more than that observed in SAP chelates. Curiously, and despite that fact that LnDOTMA chelates exhibit a preference for the TSAP isomer, ${ }^{15}$ the $\mathrm{N}-\mathrm{C}-\mathrm{C}-\mathrm{O}$ torsion angles of $\mathrm{H}_{6}$ DOTMA are greater than those observed in the $\mathrm{H}_{6}$ DOTA structure, and this leads to a shortening of the distance between the $\mathrm{N}_{4}$ and $\mathrm{O}_{4}$ planes relative to DOTA, the opposite situation to that observed in the $\mathrm{Gd}^{3+}$ chelates. ${ }^{15}$ 
The conformations of both $\mathrm{H}_{6}$ DOTMA and $\mathrm{H}_{6}$ DOTA observed in the crystal are reminiscent of how any DOTA-type ligand is commonly drawn ${ }^{34}$ in the mechanism of chelate formation elucidated by Brücher and co-workers. ${ }^{30}$ As such they represent a logical starting point for an investigation into how the ligand conformation during the initial formation of $\mathrm{H}_{2} \mathrm{LnL}^{+}$chelates might affect the regioisomeric ratio of chelates. If this conformation of ligand is predominant in solution then only if both side and corner positions of the macrocycle can accommodate the nitrobenzyl substituent is it possible for both regioisomeric chelates to be formed. A conformational analysis was performed using MM+ molecular modeling calculations to establish which of the eight equatorial positions of the aza-crown in $\mathrm{H}_{6}$ DOTMA accommodated a benzyl substituent with the lowest energy penalty. A benzylic substituent was introduced into each equatorial position in turn and an energy minimization of the substituent performed while the structure of the remainder of the ligand (macrocycle and pendant arms) was constrained. The calculated energies of each resulting conformer are summarized (Table 6). From these data it is clear that in this highly protonated form, a ligand that accommodates the benzyl substituent on any corner of the macrocycle is lower in energy than one that positions it on the side. Because each ethylene bridge is rendered inequivalent by ligand distortion, each conformer with the substituent on a corner has a different energy. However, positioning the benzyl group on a corner with a larger dihedral angle, $\mathrm{C} 3$ or $\mathrm{C} 7$ rather than $\mathrm{C} 1$ or $\mathrm{C} 5$, results in the lowest energy conformations of all. Although this corresponds to the regioisomer that predominates under more concentrated reaction conditions, ${ }^{7}$ these results cannot account for the production of the second regioisomer in which the substituent is located on the side.

Suitable crystals of a diprotonated form of DOTMA could not be grown. An initial probe of the conformational preferences of this protonation state was undertaken, again using the crystal structure of $\mathrm{H}_{6}$ DOTMA as a starting point. The same MM+ modeling procedure was used as before; however, on this occasion all protons were removed from the carboxylate groups to afford an $\mathrm{H}_{2}$ DOTMA $^{2-}$ species, and no part of the ligand system was constrained during energy minimization. The results of energy minimization afforded results very similar to those obtained for $\mathrm{H}_{6}$ DOTMA; the lowest energy ligand conformation was consistently obtained when the benzylic substituent was positioned on the corner of the macrocycle. Notably the macrocyclic distortion present in the crystal of $\mathrm{H}_{6}$ DOTMA was observed to reduce considerably during this procedure which may account for the much lower energy gap observed for $\mathrm{C} 1$ in this case. This seems to indicate that regardless of the protonation state of the ligand it is not possible that all four pendant arms adopt positions on the same side for the macrocyclic ring of NB-DOTMA or 1. However, it may be that this is the case for NB-DOTA which affords only a single regioisomer of SAP and TSAP during chelate formation. Our conventional picture of the ligand during the mechanism of chelate formation $^{34}$ is in need of some refinement.

From the crystallographic data of three stereoisomeric ligands of TCE-DOTA it is apparent that a number of different ligand conformations are possible for $\alpha$-substituted DOTA-type ligand systems. ${ }^{13}$ Most interestingly, the SSRR- isomer places two pendant arms "above" the plane of the macrocycle and two "below". To achieve this conformation the helicity of two of the macrocyclic ethylene bridges are $\delta$ while two are $\lambda$. The implications for systems such as NB-DOTMA and $\mathbf{1}$, should they adopt comparable conformations, would be significant. From this starting point the $\mathrm{Ln}^{3+}$ ion may approach the ligand from either face of the macrocycle and would still encounter carboxylate ligands with which it could begin the chelation process. The next step must then be "flipping over" the two pendant arms positioned on the opposite face of the macrocyclic ring to complete the $\mathrm{H}_{2} \mathrm{LnL}^{+}$chelate. This is readily understood in the situation that gives rise to a chelate with the benzylic substituent on the corner of the ring (Figure 7). The two pendant arms to be "flipped" are associated with ethylene bridges in the $\lambda$ conformation. Since the macrocycle must adopt a 
$\delta \delta \delta \delta$ conformation in the final chelate to accommodate an $S$ - configuration at carbon these two ethylene bridges must also flip conformations. When this occurs the two pendant arms will also "flip" onto the other side of the macrocyclic ring thereby completing the $\mathrm{H}_{2} \mathrm{LnL}^{+}$ chelate. Subsequent deprotonation of the macrocycle will allow the $\mathrm{Ln}^{3+}$ ion to drop down into the coordination cage completing the chelation reaction affording a chelate with the substituent located on the corner.

However, the $\mathrm{Ln}^{3+}$ ion need not necessarily approach from that face of the macrocycle. It could equally arrive from the opposite direction in which case it will begin the chelation process with those pendant arms associated with the $\lambda$ ethylene bridges. The $\delta$ ethylene bridges cannot flip their conformation to bring the remaining pendant arms into position because of the locking effect of the benzylic substituent. Thus an alternative route is necessary if this collision is to leads to reaction. The $\lambda$ ethylene bridges must flip their conformations since the conformations of all ethylene bridges in the final chelate must be the same, and $\delta$ to accommodate the $S$ - configuration at carbon. However, to achieve this, and keep the two pendant arms that are already interacting with the $\mathrm{Ln}^{3+}$ ion in the same position, a positional shift occurs. Every atom in the macrocycle shifts round the ring one position. In this way the $\lambda$ ethylene bridges can flip to $\delta$ inducing a "flip" in the pendant arms such that all four are positioned on the same side of the macrocyclic ring as the $\mathrm{Ln}^{3+}$ ion. Of course the consequence of this, which can only be observed in substituted macrocycles, is that position of the benzylic substituent is also shifted one place, from the corner of the ring to the side (Figure 8). When the $\mathrm{Ln}^{3+}$ ion drops down into the coordination cage after deprotonation of the macrocycle, this positional change of the benzylic substituent is fixed in place, and a regioisomer with a substituent on the side is produced.

This proposed ligand conformation accounts for the production of two regioisomeric chelates during the metalation reactions of NB-DOTMA and 1. It also accounts for the observed $\mathrm{pH}$ and concentration dependence of the product ratios since the reactions described in Figure 7 and 8 are likely to have different reaction rates under different conditions. Furthermore, the mechanism proposed is not restricted to a "two up two down" ligand conformation; it would also encompass "three up one down" and "one up three down" conformations. However, we are able to exclude the involvement of "four up" or "four down" conformations under these reaction conditions since they would produce a single regioisomeric product. The involvement of these latter conformations in the formation of chelates from unsubstituted macrocycles, such as those of DOTA and DOTMA, can not be ruled out since differentiation of the two products is not possible. It is also possible that they are involved in the formation of NB-DOTA chelates, although this seems unlikely; it is more probable that simply the rate of the reaction shown in Figure 8 is just so slow that it does not contribute to the overall product distribution.

\section{Thermodynamic Stability}

Since $\mathrm{Ln}^{3+}$ ions are not well tolerated in vivo, extremely strong chelates are required for in vivo applications to ensure that the $\mathrm{Ln}^{3+}$ ion is not released into the body. Determining the stability constant is an excellent means of assessing the strength of a chelate. The stability constants of chelates that form rapidly, such as $\mathrm{H}_{2} \mathrm{GdL}^{+}$vide infra, can be obtained from direct titration of the ligand in the presence of the metal ion. The complete chelation of $\mathrm{Ln}^{3+}$ ions by DOTA-type ligands occurs only very slowly. For these systems a different, out-ofcell, ${ }^{21}$ approach is required. The $\mathrm{pH}$ of a series of samples containing ligand and metal are adjusted to different values in the range of 1.82-2.90. The samples are then sealed and incubated at $40{ }^{\circ} \mathrm{C}$ for 2 months followed by a further 3 months at room temperature. The $\mathrm{pH}$ of each solution is then recorded. This "out-of-cell" approach allows points on a titration curve to be determined accurately, and subsequent comparison with the titration data 
obtained for the ligand in isolation affords the stability constant. Stability constants were determined, using a $1.0 \mathrm{M} \mathrm{KCl}$ ionic background, for the $\mathrm{Ce}^{3+}, \mathrm{Gd}^{3+}$, and $\mathrm{Yb}^{3+}$ chelates of $S$-RRRR-NB-DOTMA (SAP) and S-SSS-1 (TSAP); the data are collected in Table 7.

The trend most generally observed for the $\mathrm{Ln}^{3+}$ chelates of a given ligand is that the thermodynamic stability increases as the ionic radius of the $\mathrm{Ln}^{3+}$ ion becomes smaller. This is easily understood in terms of an increased electrostatic interaction as the $\mathrm{Ln}^{3+}$ ions become more charge dense across the series. However, in the cases of the two ligands under investigation here an additional factor comes into play. In LnDOTA chelates, the SAP and TSAP structures may interconvert freely in solution, and the distribution of these two isomers is determined by the relative energy of each. It is well-known that in chelates of the larger, earlier lanthanides the TSAP isomer, which has a more open coordination cage, predominates. ${ }^{14}$ As one passes along the series the SAP isomer becomes increasingly more populated as the ionic radius of the $\mathrm{Ln}^{3+}$ ions decreases, reaching a maximum when the ionic radius is $\sim 104 \mathrm{pm}$. This occurs between $\mathrm{Ho}^{3+}$ and $\mathrm{Er}^{3+}$, henceforth, as the ionic radius continues to decrease the TSAP isomer becomes increasingly more populated. ${ }^{14}$ This reversal in the trend is apparently a result of the coordinated water molecule that caps the TSAP structure being pushed off the chelate entirely by the steric demands of a ligand in a TSAP conformation. ${ }^{14,35}$

For chelates of both $S$-RRRR-NB-DOTMA and $S$-SSS-1 isomeric interconversion is not possible; the coordination geometry is fixed. It is perhaps not surprising then the stability constants should follow the trend observed for the SAP/TSAP isomer distribution in LnDOTA chelates. $S$-SSS-1, which is obliged to adopt a TSAP structure, forms its most stable chelate with $\mathrm{Ce}^{3+}$, the largest ion studied. Conversely, the stability constant of CeS$R R R R$-NB-DOTMA, constrained to adopt the less favorable SAP isomer, is the smallest of any of the chelates studied and $4.25 \mathrm{log}$ units lower than that of the TSAP isomer. By the time one reaches GdDOTA the SAP isomer is already the predominant isomer in solution, constituting $\geq 85 \%$ of the sample. Not surprisingly then, the observed stability of $\mathrm{Gd} S$ $R R R R$-NB-DOTMA was determined to be much higher, $\sim 4 \log$ units higher than that of the corresponding $\mathrm{Ce}^{3+}$ chelate and $\sim 2 \log$ units higher than that of $\mathrm{Gd} S$-SSS-1. The isomer distribution in YbDOTA is comparable to that of GdDOTA and this too is reflected in the stability constants of both $\mathrm{YbS}-R R R R$-NB-DOTMA and YbS-SSS-1 which are just slightly higher than that observed for the corresponding $\mathrm{Gd}^{3+}$ chelates. The slightly higher stability constants determined for the $\mathrm{Yb}^{3+}$ chelates, relative to the $\mathrm{Gd}^{3+}$ chelates, is then presumably the result of the aforementioned increased electrostatic interaction between ligand and metal ion. This observation should not be misinterpreted as reflecting selectivity for one metal ion over another by each ligand. ${ }^{36}$

It is instructive to compare these stability constants with those obtained for LnDOTA chelates. ${ }^{25}$ In each case the $K_{\mathrm{LnL}}$ for DOTA closely matches that of whichever chelate was constrained to adopt the predominant solution state isomer of LnDOTA for a given $\mathrm{Ln}^{3+}$ ion. So CeDOTA, in which the TSAP isomer predominates, has a stability constant that is comparable to that of CeS-SSS-1 which is constrained to adopt a TSAP geometry. In the same way the $\mathrm{Gd}^{3+}$ and $\mathrm{Yb}^{3+}$ chelates of both DOTA and NB-DOTA, ${ }^{21}$ all predominately SAP, have very similar stability constants to the $S$ - $R R R R$-NB-DOTMA chelates which are constrained into a SAP geometry. It should be noted that the stability constant data reported herein do not separate contributions from the two regioisomers (side and corner) of these chelates discussed above. Each regioisomer is expected to contribute differently to the overall measurement; however, the extent of each contribution remains unknown and difficult to probe. 


\section{Epimerization Is Not a Route to Isomer Selection}

We have previously shown that chiral centers in the $\alpha$-position of acetate pendant arms can be epimerized when the chelate is subjected to acid, below $\sim \mathrm{pH} 2 .{ }^{13}$ This epimerization will, over time, favor the lowest energy configuration at each chiral center and leads to the eventual production of a single diastereoisomer: the RRRR-/SSSS- isomer. In the case of nitrobenzyl substituted chelates the $R R R R$ - and SSSS- isomers are not equivalent, affording SAP and TSAP isomers, respectively when the configuration at the macrocycle is $S$-. This raised the prospect of examining the relative stability of the two isomers by epimerization. As a preliminary experiment we examined a sample of YbS-SSS-1 a chelate constrained to adopt a TSAP geometry despite a preference of $\mathrm{Yb}^{3+}$ for the SAP geometry. ${ }^{14}$ If the $\alpha$ chiral centers of this chelate could be induced to epimerize then would it slowly convert, through other diasteroisomers, from a TSAP isomer to the more thermodynamically stable SAP isomer? Accordingly, a $20 \mathrm{mM}$ sample of optically pure chelate was prepared in $\mathrm{D}_{2} \mathrm{O}$ at $\mathrm{pD} 1(\mathrm{DCl})$ and sealed in an NMR tube. The choice of deuterated solvent was critical as it allowed for verification that epimirization of the $\alpha$ - centers was occurring by monitoring for deuterium incorporation. The sample was then incubated at $90{ }^{\circ} \mathrm{C}$ and monitored periodically by ${ }^{1} \mathrm{H}$ NMR.

A second chelate was observed to slowly grow in the NMR spectrum of the sample over a period of several weeks. However, this new chelate did not exhibit a SAP coordination geometry (Figure 9), nor did the $\alpha$-methyne protons (shifted most upfield and not shown) diminish in signal intensity. From this latter observation we can conclude that in this chelate no epimerization of the $\alpha$ - centers occurs under these conditions since there is no H/D exchange. Consequently, the only means by which a second chelate structure can be produced is if the metal ion is liberated from the initial chelate by the acid in the sample, and metal and ligand then recombine. Under such circumstances two possible reaction routes are open. First, they can recombine in a reverse reaction to form the initial chelate. Second, they could undergo a recombination reaction that shifts the position of the nitrobenzyl substituent as indicated in Figure 8, thereby producing the regioisomer of the initial chelate. Figure 9 shows the ${ }^{1} \mathrm{H}$ NMR spectra of the initial chelate YbS-SSS-1 in which the nitrobenzyl group is located on the corner of the macrocycle, the same sample after $336 \mathrm{~h}$ of heating at $\mathrm{pD} 1$ and $90{ }^{\circ} \mathrm{C}$ and the sample of a YbS-SSS-1 in which the nitrobenzyl group is located on the side of the macrocycle. This last sample was isolated as a side product from the reaction that produced the sample with the substituent on the corner. From these NMR spectra it is clear that the position of the nitrobenzyl substituent is being scrambled during this process to afford a mixture of chelates in which the nitrobenzyl substituent is either located on the corner or the side of the macrocyclic ring. The development of this latter regioisomer over time is shown in Figure 10, which indicates that an equilibrium point will eventually be reached. Although the position of this equilibrium point is undoubtedly dependent upon the $\mathrm{pH}$ and presumably also the reaction temperature, in this case it lies close to 50/50. Further studies would be required to probe whether this end point is the result of thermodynamics or the kinetics of the various reaction processes involved.

\section{CONCLUSIONS}

Our previously reported conclusions regarding the chelates obtained when preparing NB-

DOTMA chelates were mistaken. Although the amine in the 1-position of the macrocycle is undoubtedly a poorer nucleophile than those in the other positions of the ring, it is sufficiently powerful to undertake an $\mathrm{S}_{\mathrm{N}} 2$ reaction. Thus, the alkylation reaction produces a single ligand stereoisomer; however, when a chelate is formed from this single stereoisomer two regioisomeric chelates may result. The distribution of these regioisomeric chelates produced is dependent upon the reaction conditions employed during metalation. This observation of the formation of regioisomeric chelates may also explain the production of 
multiple isomeric chelates in the related $\mathrm{Cu}^{2+}$ chelates of NB-NOTA. ${ }^{37}$ We hypothesize that the production of more than one regioisomer during the chelation process stems from the conformation of the ligand in solution before the formation of the intermediate $\mathrm{H}_{2} \mathrm{LnL}^{+}$ complex. This conformation must involve placing pendant arms on either side of (above and below) the macrocyclic ring. It also would seem likely that a mixture of $\delta$ and $\lambda$

conformations is present for the ethylene bridges within each macrocyclic ring. The regioisomer obtained is thus dependent upon the face from which the metal approaches the ligand and how the ligand rearranges both the pendant arms and the ethylene bridge conformations to form the $\mathrm{H}_{2} \mathrm{LnL}^{+}$intermediate. The involvement of this intermediate has been confirmed allowing rate constants for the final rate determining step in the chelate formation. As for other related chelates the value of $k_{\mathrm{H}_{2} \mathrm{O}}$ for these nitrobenzyl ligands is small indicating that a base catalyzed pathway predominates. The rate constants for this process $k_{\mathrm{OH}^{-}}$are found to be much smaller in cases where the ligand system is substituted on the pendant arms, much more so than substitution of the macrocycle. This indicates that conformational motion of the macrocycle plays little or no part in allowing the $\mathrm{Ln}^{3+}$ ion to drop down into the coordination cage. In contrast substitution of the pendant arms, which equates to restricted conformational motion of these arms, does appear to be an important factor in the deprotonation and rearrangement of $\mathrm{H}_{2} \mathrm{LnL}^{+}$to the fully formed chelate.

The chelates produced by these conformationally restricted ligands are stable, of comparable stability to the corresponding DOTA chelates. An interesting relationship is observed between the stability constants, the size of the $\mathrm{Ln}^{3+}$ ion, and the nature of the ligand. The thermodynamic stability of a chelate is highest for DOTA-type ligands when the ligand preferentially adopts the coordination geometry most preferred by that metal ion, that is, early $\mathrm{Ln}^{3+}$ ions are more stable with $S$-SSS-1 (a TSAP ligand) whereas later $\mathrm{Ln}^{3+}$ ions preferred the $S$-RRRR-DOTMA (SAP ligand). From the data presented herein it seems apparent that these conformationally restricted chelates are stable enough for in vivo applications. However, the production of multiple regioisomers during metalation is a problem that may well prove intractable and may limit the desirability of this particular system to molecular imaging applications.

\section{Supplementary Material}

Refer to Web version on PubMed Central for supplementary material.

\section{Acknowledgments}

The authors thank the National Institutes of Health (EB-011687), Oregon Nanoscience and Microtechnologies Institute (N00014-11-1-0193); a János Bolyai Research Scholarship of the Hungarian Academy of Sciences, the Hungarian Scientific Research Found (OTKA K84291) and the TÁMOP 4.2.1./B-09/1/KONV-2010-0007 project implemented through the New Hungary Development Plan, cofinanced by the European Social Fund and the European Regional Development Fund (G.T.); the M.J. Murdock Charitable Trust, Portland State University and the Oregon Opportunity for biomedicine for financial support of this work and the National Science Foundation (0741993) for funding the purchase of the LTQ-Orbitrap Discovery. This research was performed within the framework of the EU COST Action D38 "Metal-Based Systems for Molecular Imaging Applications".

\section{REFERENCES}

1. Caravan P, Ellison JJ, McMurry TJ, Lauffer RB. Chem. Rev. 1999; 99(9):2293-2352. [PubMed: 11749483]

2. Xu J, Franklin SJ, Whisenhunt DW Jr, Raymond KN. J. Am. Chem. Soc. 1995; 117(27):7245-7246.

3. Burai L, Toth E, Merbach AE. Chem. Commun. 2003; 21:2680-2681.

4. Laus S, Ruloff R, Toth E, Merbach AE. Chem.-Eur. J. 2003; 9(15):3555-3566.

5. Kotek J, Lebduskova P, Hermann P, Van der Elst L, Muller RN, Geraldes CFGC, Maschmeyer T, Lukes I, Peters JA. Chem.-Eur. J. 2003; 9(23):5899-5915. 
6. Woods M, Kovacs Z, Zhang S, Sherry AD. Angew. Chem., Int. Ed. 2003; 42(47):5889-5892.

7. Woods M, Botta M, Avedano S, Wang J, Sherry AD. Dalton Trans. 2005; 24:3829-3837. [PubMed: 16311635]

8. Rudovsky J, Cigler P, Kotek J, Hermann P, Vojtisek P, Lukes I, Peters JA, Vander Elst L, Muller RN. Chem.-Eur. J. 2005; 11(8):2373-2384.

9. Aime S, Botta M, Ermondi G. Inorg. Chem. 1992; 31(21):4291-4299.

10. Hoeft S, Roth K. Chem. Ber. 1993; 126(4):869-873.

11. Aime S, Barge A, Bruce JI, Botta M, Howard JAK, Moloney JM, Parker D, de Sousa AS, Woods M. J. Am. Chem. Soc. 1999; 121(24):5762-5771.

12. Dunand FA, Aime S, Merbach AE. J. Am. Chem. Soc. 2000; 122(7):1506-1512.

13. Woods M, Aime S, Botta M, Howard JAK, Moloney JM, Navet M, Parker D, Port M, Rousseaux O. J. Am. Chem. Soc. 2000; 122(40):9781-9792.

14. Aime S, Botta M, Fasano M, Marques MPM, Geraldes CFGC, Pubanz D, Merbach AE. Inorg. Chem. 1997; 36(10):2059-2068. [PubMed: 11669824]

15. Aime S, Botta M, Garda Z, Kucera BE, Tircso G, Young VG, Woods M. Inorg. Chem. 2010

16. SMART, V5.054. Madison, WI: Bruker Analytical X-ray Systems; 2001.

17. Blessing RH. Acta Crystallogr. 1995; A51(1):33-38.

18. SAINT+, V6.45. Madison, WI: Bruker Analytical X-Ray Systems; 2003.

19. SHELXTL, V6.14. Madison, WI: Bruker Analytical X-Ray Systems; 2000.

20. Irving HM, Miles MG, Pettit LD. Anal. Chim. Acta. 1967; 38(4):475.

21. Woods M, Kovacs Z, Kiraly R, Brücher E, Zhang S, Sherry AD. Inorg. Chem. 2004; 43(9):28452851. [PubMed: 15106971]

22. Zékány, L.; Nagypál, I. Computational Methods for Determination of Formation Constants. In: Legget, DJ., editor. Computational Methods for Determination of Formation Constants. New York: Kluwer; 1985. p. 291

23. Meyer M, Dahaoui-Gindrey V, Lecomte C, Guilard R. Coord. Chem. Rev. 1998; 178-180(Pt. 2): 1313-1405.

24. Di Bari L, Pescitelli G, Sherry AD, Woods M. Inorg. Chem. 2005; 44(23):8391-8398. [PubMed: 16270977]

25. Cacheris WP, Nickle SK, Sherry AD. Inorg. Chem. 1987; 26(6):958-960.

26. Hancock RD, Motekaitis RJ, Mashishi J, Cukrowski I, Reibenspies JH, Martell AE. J. Chem. Soc., Perkin Trans. 1996; 2(No. 9):1925-1929.

27. Delgado R, da Silva JJ. Talanta. 1982; 29(10):815-822. [PubMed: 18963244]

28. Kalman FK, Woods M, Caravan P, Jurek P, Spiller M, Tircso G, Kiraly R, Brucher E, Sherry AD. Inorg. Chem. 2007; 46(13):5260-5270. [PubMed: 17539632]

29. Smith RM, Martell AE. Sci. Total Environ. 1987; 64(1-2):125-147.

30. Tóth É, Brücher E, Lázár I, Tóth I. Inorg. Chem. 1994; 33(18):4070-4076.

31. Moreau J, Guillon E, Pierrard J-C, Rimbault J, Port M, Aplincourt M. Chem.-Eur. J. 2004; 10(20):5218-5232.

32. Wu SL, Horrocks WD Jr. Inorg. Chem. 1995; 34(14):3724-3732.

33. Wang X, Jin T, Comblin V, Lopez-Mut A, Merciny E, Desreux JF. Inorg. Chem. 1992; 31(6): 1095-1099.

34. Sherry AD, Caravan P, Lenkinski Robert E. Magn. Reson. Imaging. 2009; 30(6):1240-1248.

35. Benetollo F, Bombieri G, Calabi L, Aime S, Botta M. Inorg. Chem. 2003; 42(1):148-157. [PubMed: 12513089]

36. Di Bernardo P, Zanonato PL, Bismondo A, Melchior A, Tolazzi M. Dalton Trans. 2009; 21:42364244. [PubMed: 19452074]

37. Schlesinger J, Rajander J, Ihalainen JA, Ramesh D, Eklund P, Fagerholm V, Nuutila P, Solin O. Inorg. Chem. 2011; 50(10):4260-4271. [PubMed: 21488661] 

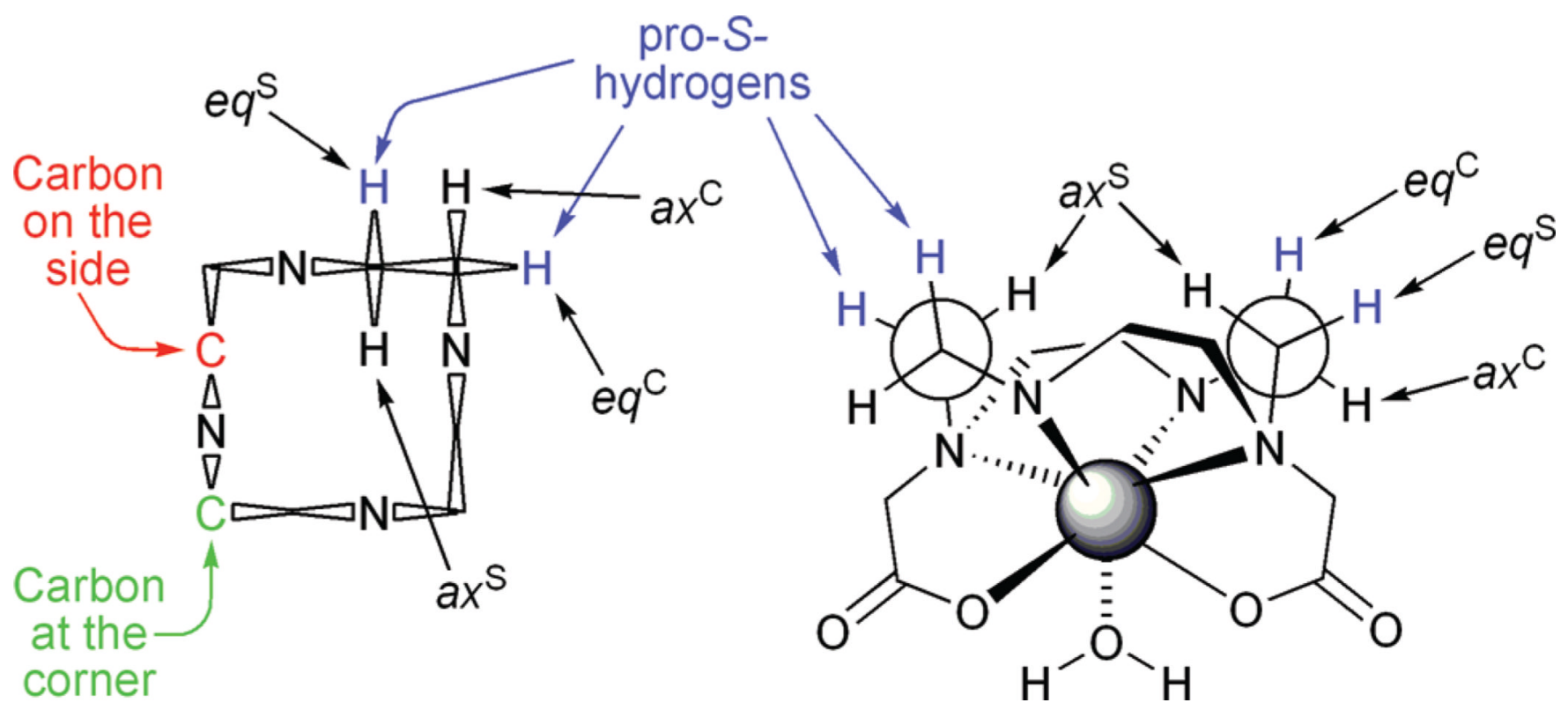

Figure 1.

Schematic representations of the conformation of cyclen in DOTA-type chelates. Left: A Dale's representation of the [3333] ring conformation of cyclen in the $\delta \delta \delta \delta$ conformation highlighting the differences between carbons located at a corner position versus those located at a side position. Right: Highlighting a Newman projection of the ethylene bridges, again in a $\delta \delta \delta \delta$ conformation, demonstrating that equatorial positions on both carbons located at the corner and at the side are pro- $S$ - 


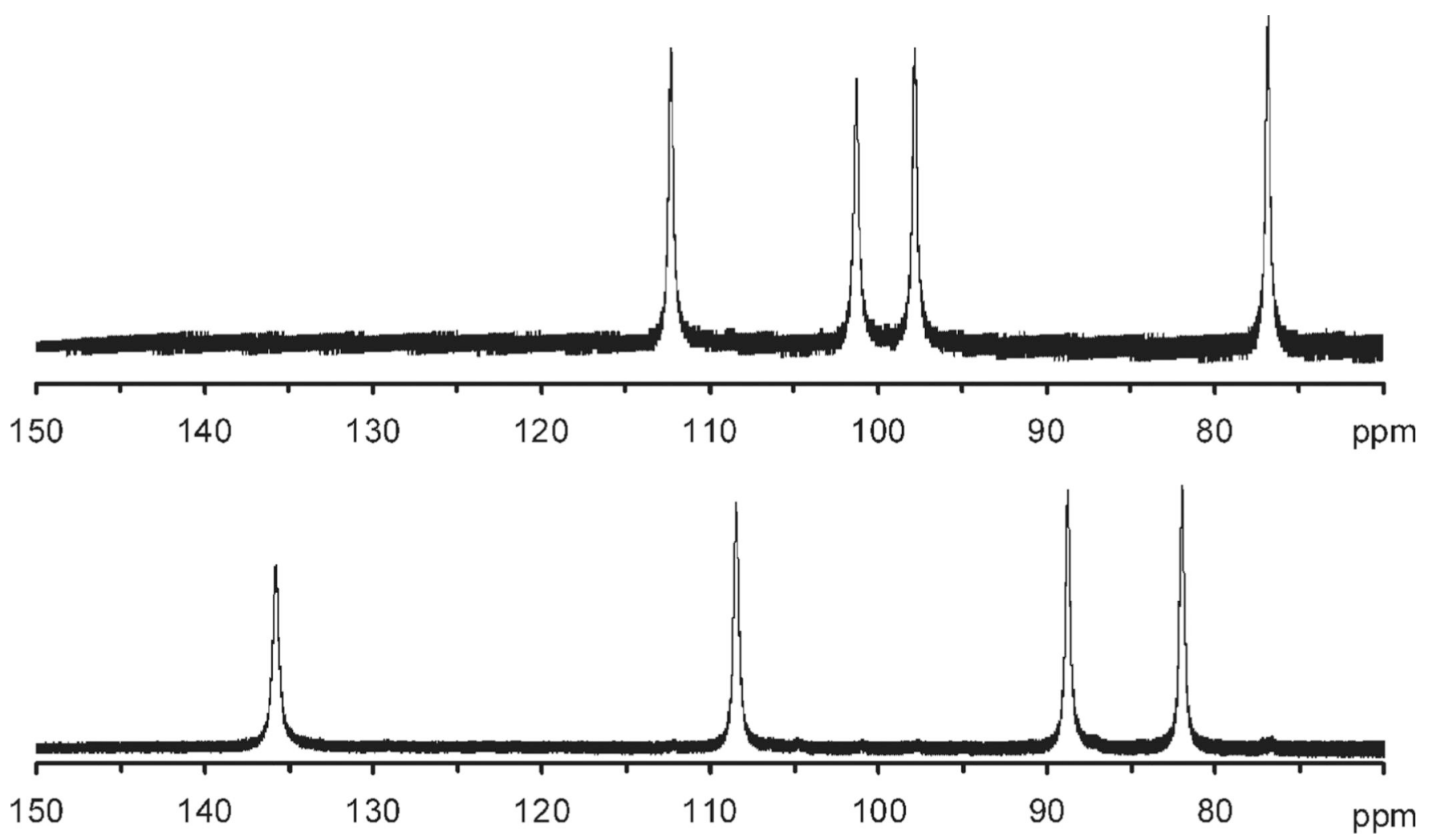

Figure 2.

Expansion of the hyper-shifted region of the ${ }^{1} \mathrm{H}$ NMR spectra $\left(300 \mathrm{MHz}, \mathrm{D}_{2} \mathrm{O}\right)$ of two isomeric chelates of YbNB-DOTMA (both TSAP coordination isomers) focusing on the $a x^{S}$ protons of the macrocyclic ring. Previously these two isomers were ascribed to the $S$-SSSS(top) and $S$-RSSS- (bottom) isomers. ${ }^{7,24}$ This assignment is now understood to be erroneous, in fact these spectra correspond to two regioisomers of the S-SSSS- isomer in which the nitrobenzyl substituent is located on the corner (top) and on the side (bottom) of the macrocyclic ring, see Figure 1. 


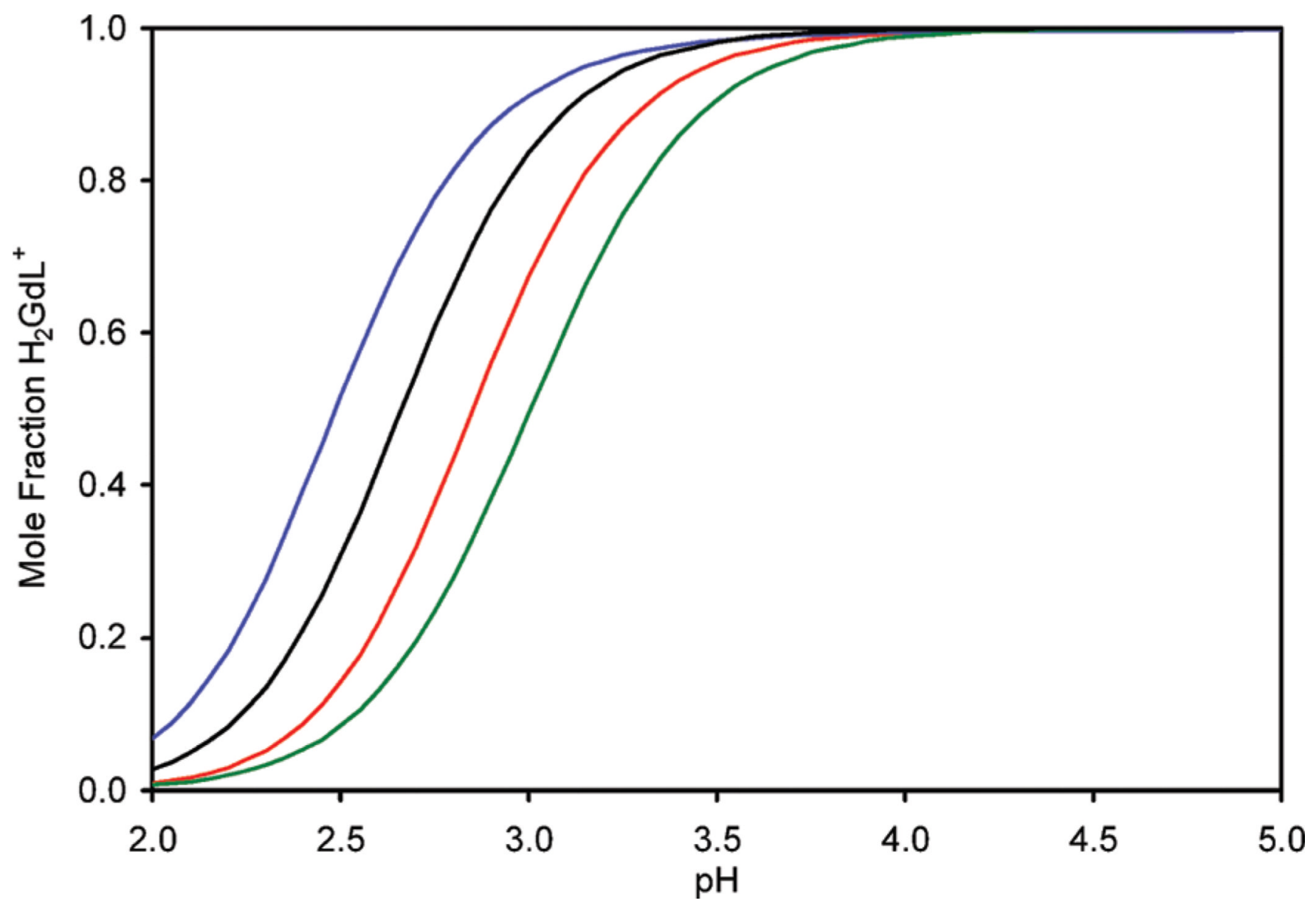

Figure 3.

Mole fraction of $\mathrm{H}_{2} \mathrm{GdL}^{+}$present in solution as a function of $\mathrm{pH}$ for $S$-RRRR-NB-DOTMA (blue), DOTMA (black), NB-DOTA (red), and S-SSS-1 (green). 


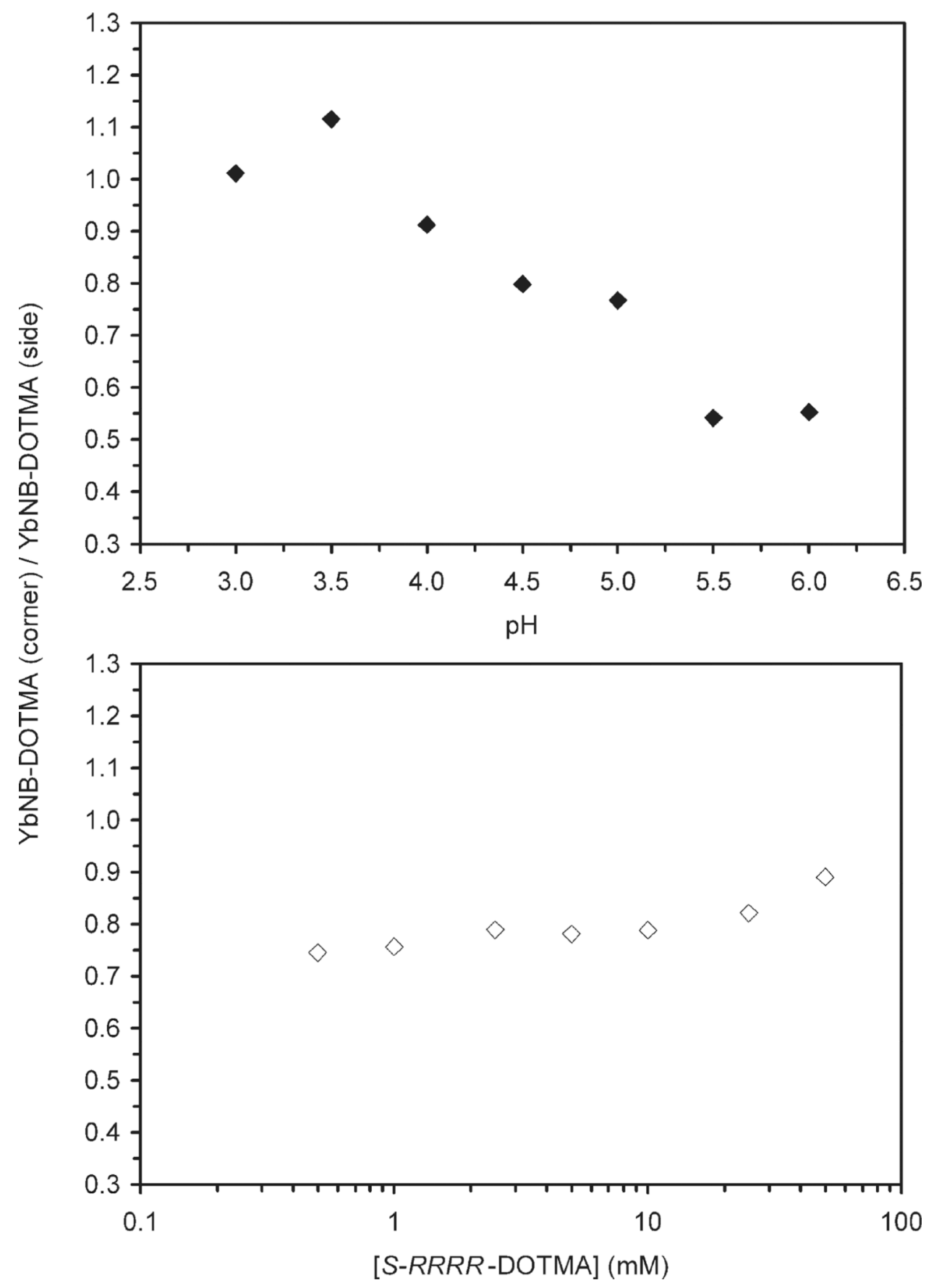

Figure 4.

Ratio of YbS-RRRR-DOTMA chelates with the nitrobenzyl substituent positioned on the corner of the macrocycle (YbNB-DOTMA (corner)) and that with the nitrobenzyl substituent positioned on the side of the macrocycle (YbNB-DOTMA (side)) formed during chelate formation (a) at $7.1 \mathrm{mM}$ as a function of $\mathrm{pH}$ in a series of $1.0 \mathrm{M}$ buffers, (b) as a function of initial ligand concentration at $\mathrm{pH} 5.5$ in $1.0 \mathrm{M} \mathrm{NaOAc}$ buffer. All reactions were incubated for 64 days at $70{ }^{\circ} \mathrm{C}$. 

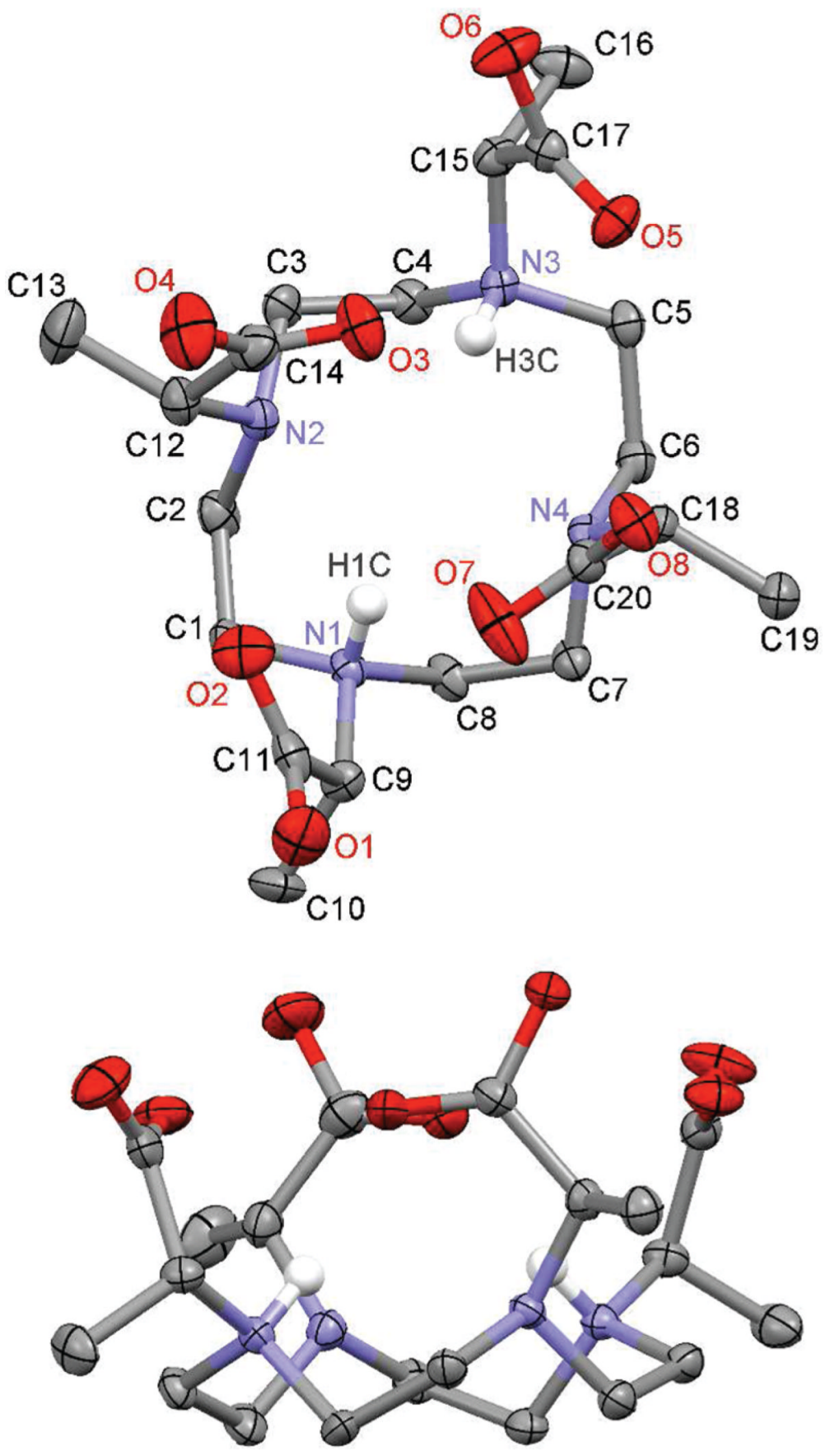

Figure 5.

$50 \%$ Thermal ellipsoid plot of the crystal structure of $\mathrm{H}_{4}$ DOTMA $\bullet 2 \mathrm{HCl} \cdot 3 \mathrm{H}_{2} \mathrm{O}$. All hydrogen atoms, except those protonating amines, have been omitted for clarity as have water molecules and chloride counterions. All carboxylates are protonated on $\mathrm{O} 2, \mathrm{O} 4, \mathrm{O} 6$, and $\mathrm{O} 8$. 

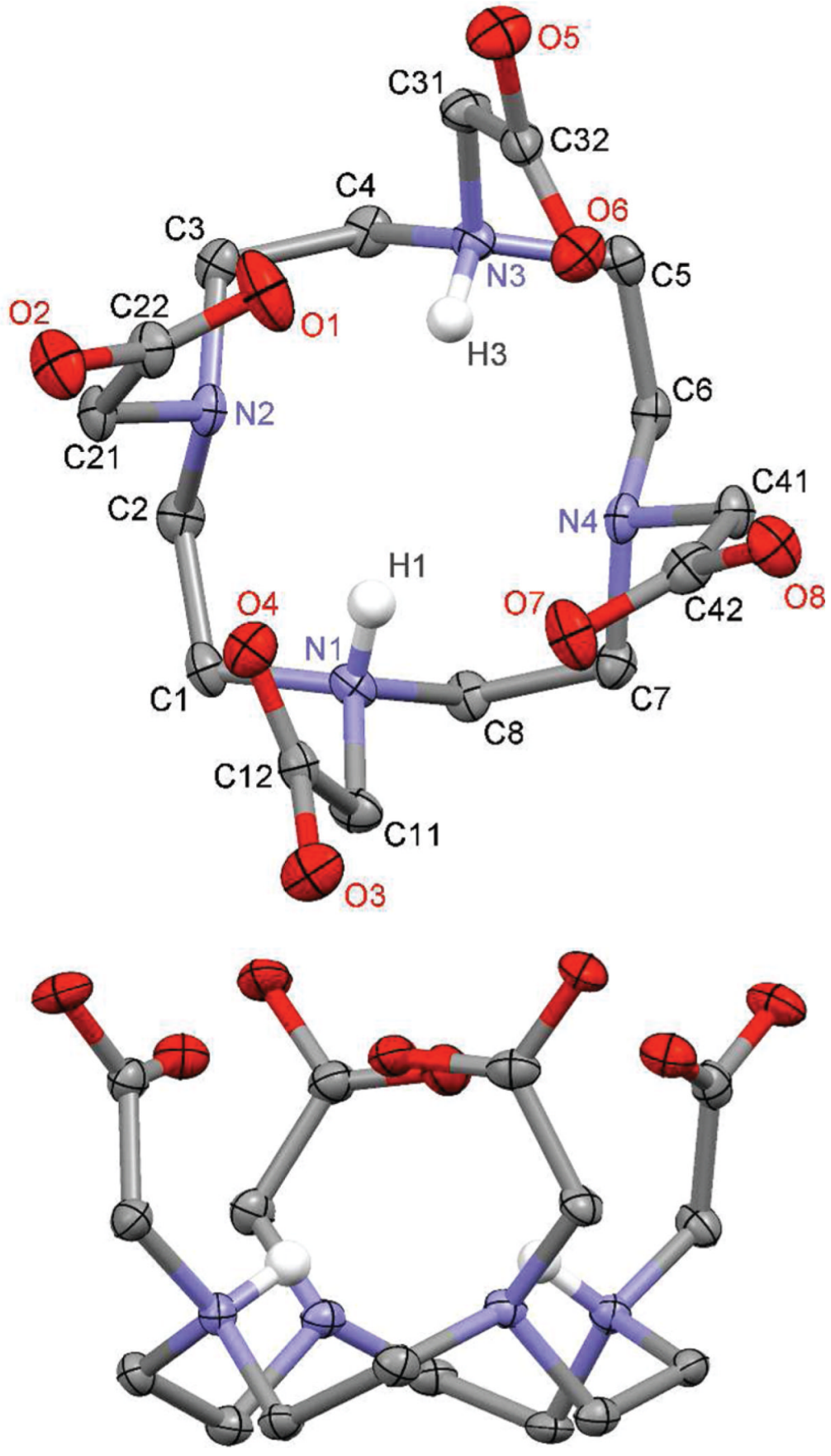

Figure 6.

$50 \%$ Thermal ellipsoid plot of the crystal structure of $\mathrm{H}_{4} \mathrm{DOTA} \cdot 2 \mathrm{HCl} \cdot 5 \mathrm{H}_{2} \mathrm{O}$, reported in reference 11. All hydrogen atoms, except those protonating amines, have been omitted for clarity as have water molecules and chloride counterions. All carboxylates are protonated; protons are located on $\mathrm{O} 2, \mathrm{O} 3, \mathrm{O} 5$, and $\mathrm{O} 8$. 
Side view
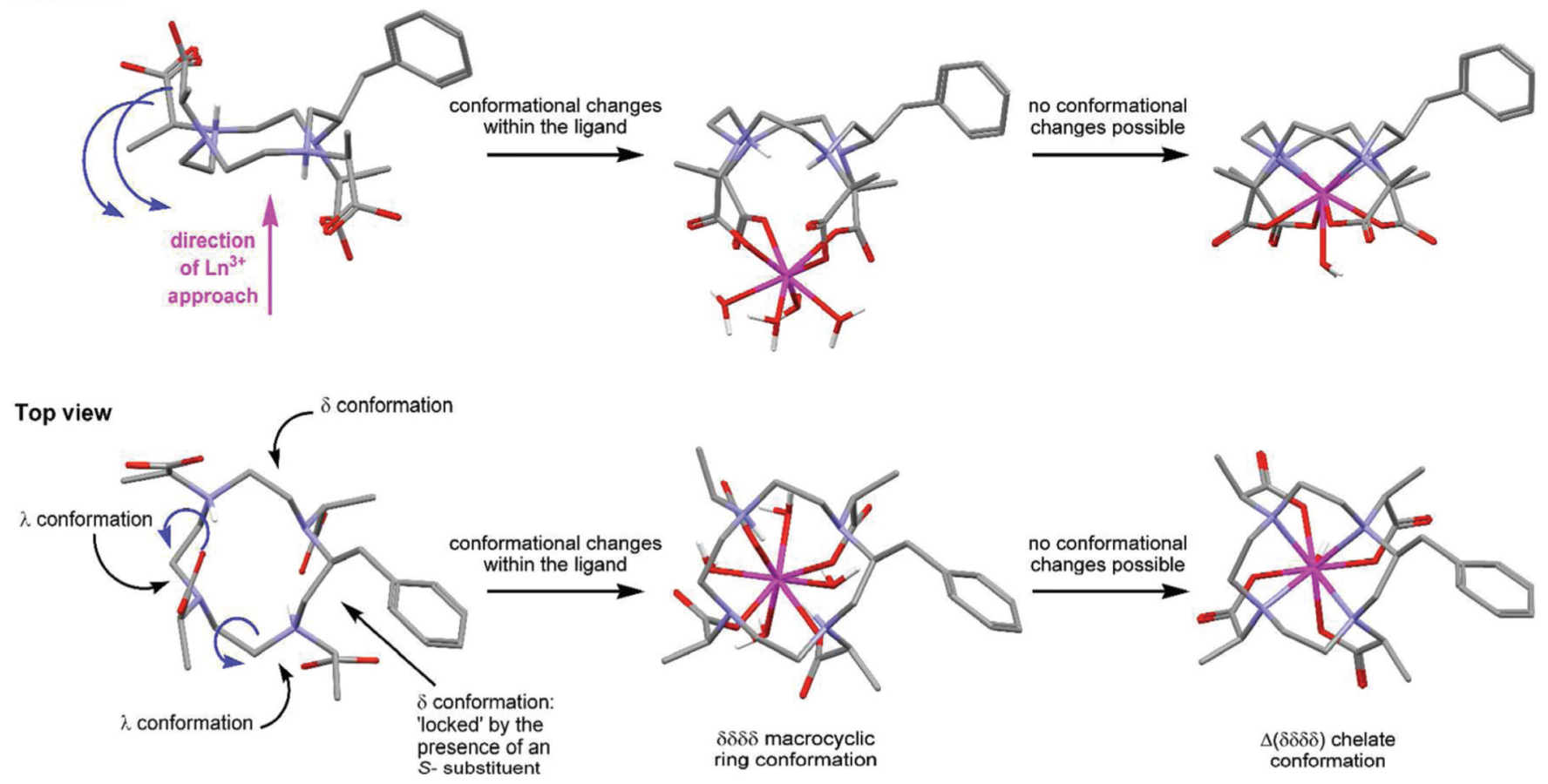

Figure 7.

Conformational changes that are hypothesized to occur during the formation of a chelate that positions the benzylic substituent on the corner of the macrocycle, shown for the $S$-SSSSisomer of NB-DOTMA. The ligand structure is derived from the crystallographic data for RRSS-TCE-DOTA and the benzylic substituent located in the position found to afford the lowest energy conformation, vide infra. To flip the pendant arms on the left-hand sight of the macrocycle below the plane of the macrocycle as shown (blue arrows) the conformation of two ethylene bridges must flip $\lambda \lambda$ to $\delta \delta$ (blue arrows). 
Side view
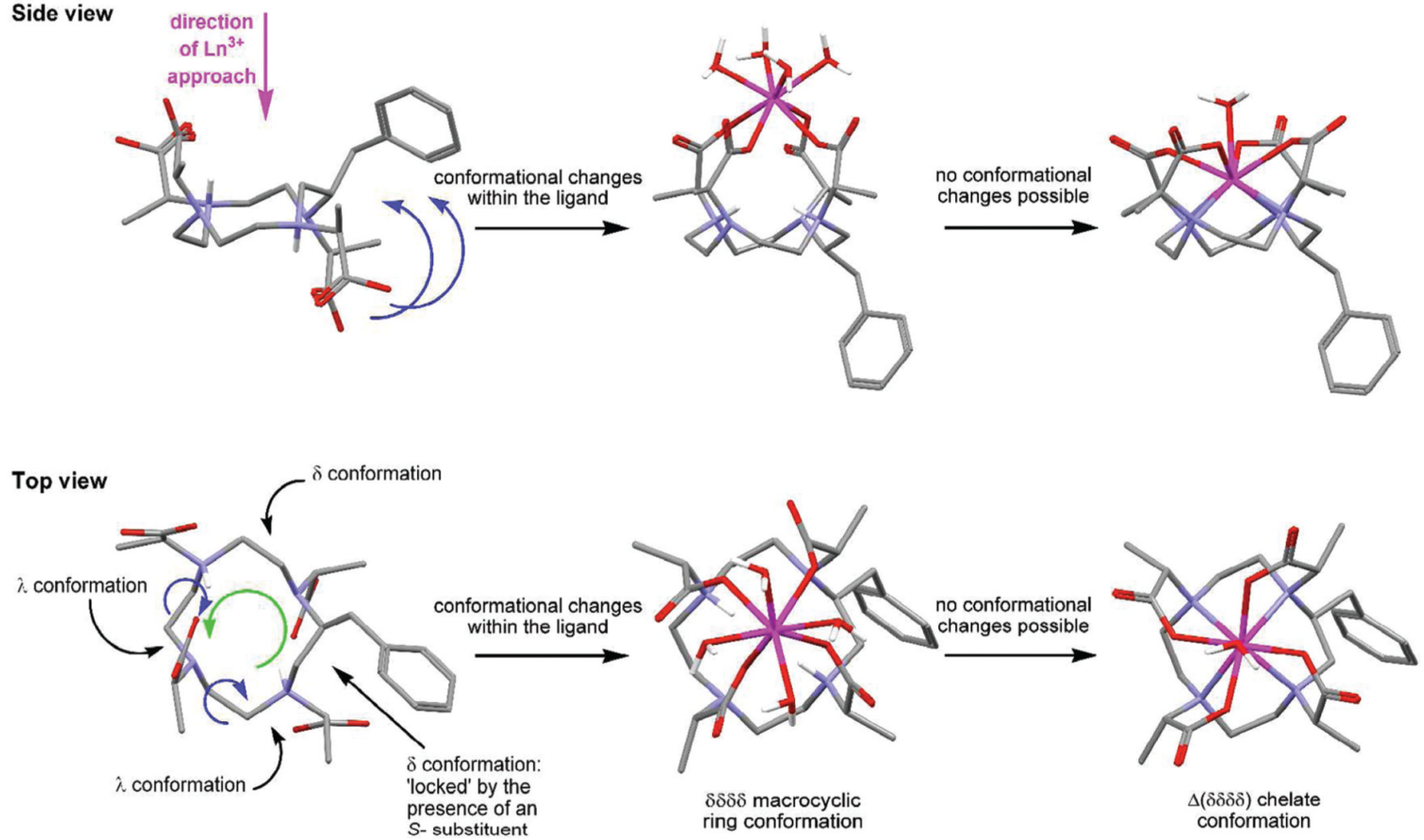

Figure 8.

Conformational changes that are hypothesized to occur during the formation of a chelate that positions the benzylic substituent on the side of the macrocycle, shown for the S-SSSSisomer of NB-DOTMA. The ligand structure is derived from the crystallographic data for $R R S S$-TCE-DOTA and the benzylic substituent located in the position found to afford the lowest energy conformation, vide infra. To flip the two pendant arms in the right-hand side of the ligand above the plane of the macrocycle (as shown) it is necessary for each atom in the macrocycle to undergo a positional shift (green arrow) which enable the two ethylene bridges in a $\lambda$ conformation to flip conformations while flipping the pendant arms on the right into a position above the ring (blue arrows). This positional shift also moves the benzylic substituent from the corner (in the ligand) to the side of the macrocycle (in the chelate). 

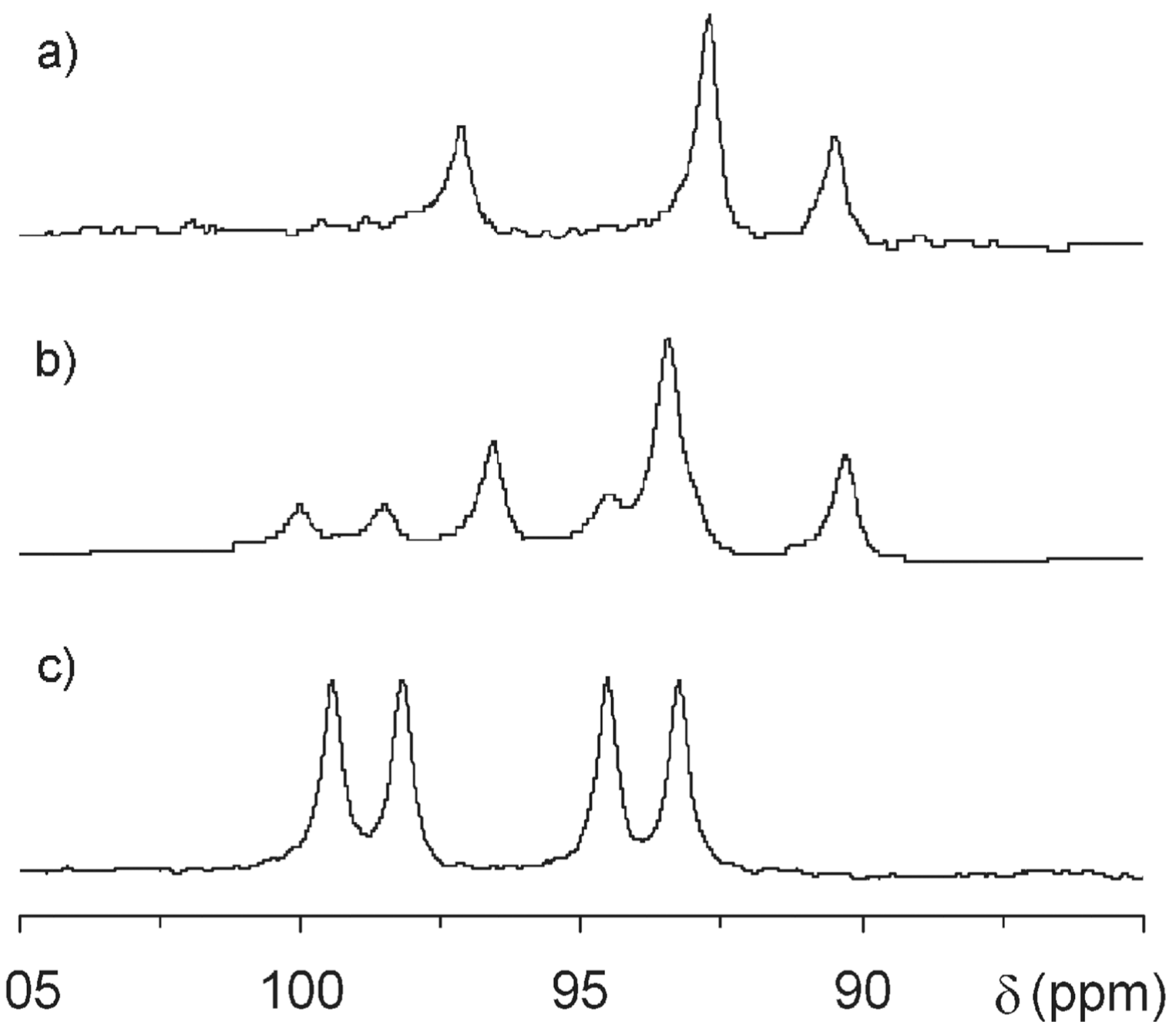

Figure 9.

${ }^{1} \mathrm{H}$ NMR spectra $\left(600 \mathrm{MHz}, \mathrm{D}_{2} \mathrm{O}\right)$, focusing on the $a x^{\mathrm{s}}$ resonances, of (a) a sample of $\mathrm{YbS}$ SSS-1 with the nitrobenzyl group located on the corner of the macrocycle; (b) the same sample after heating for $336 \mathrm{~h}$ at $90{ }^{\circ} \mathrm{C}$ and $\mathrm{pD} 1$; and (c) a sample of YbS-SSS-1 with the nitrobenzyl substituent located on the side of the macrocycle that was isolated from the synthesis of the sample used in (a) and (b). 


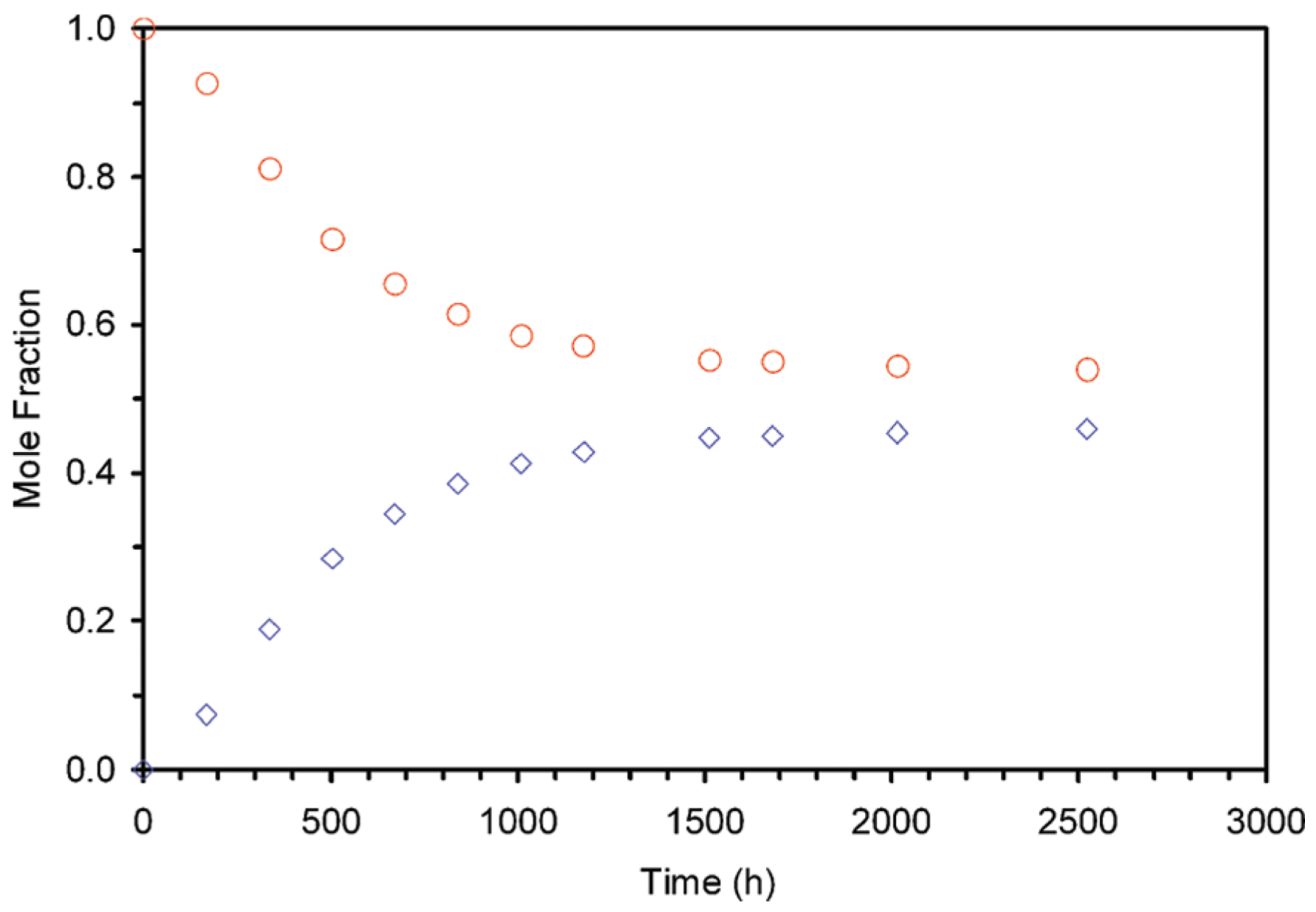

Figure 10.

Shown are the decreasing proportion $\mathrm{YbS}-S S S$-1 with the nitrobenzyl located on the corner of the macrocycle (red circles) and the corresponding increase in the proportion of $\mathrm{YbS}$ $S S S$-1 with the nitrobenzyl group located on the side of the macrocycle (blue diamonds) as determined by ${ }^{1} \mathrm{H}$ NMR as a sample of YbS-SSS-1 (with the nitrobenzyl group located on the corner of the macrocycle) is heated at pD1 and $90{ }^{\circ} \mathrm{C}$. 
<smiles>O=C(O)CN1CCN(CC(=O)O)CCN(CC(=O)O)CCN(CC(=O)O)CC1</smiles>

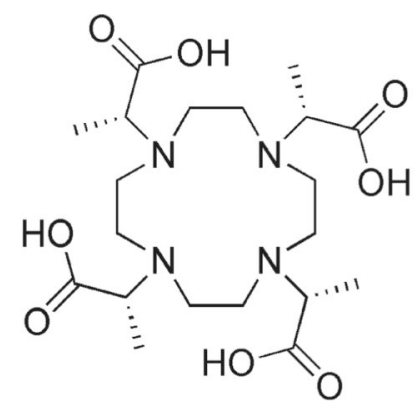

$\mathrm{H}_{4}$ DOTA

$\mathrm{H}_{4}$ DOTMA<smiles>O=C(O)CN1CCN(CC(=O)O)CCN(CC(=O)O)[C@@H](Cc2ccc([N+](=O)[O-])cc2)CN(CC(=O)O)CC1</smiles><smiles>O=C(O)CCC(C(=O)O)N1CCN(C(CCC(=O)O)C(=O)O)CCN(C(CCC(=O)O)C(=O)O)CCN(C(CCC(=O)O)C(=O)O)CC1</smiles>

$\mathrm{H}_{4}$-NB-DOTA

$\mathrm{H}_{4}$-TCE-DOTA<smiles></smiles>

$\mathrm{H}_{4}$ S-RRRR-NB-DOTMA<smiles>C[C@@H](C(=O)O)N1CCN(CC(=O)O)[C@@H](Cc2ccc([N+](=O)[O-])cc2)CN(CC(=O)O)[C@@H](C)C(=O)N([C@H](C)C(=O)O)CC1</smiles>

$\mathrm{H}_{4}$-S-SSS-1

Chart 1.

Formulae of Cyclen-Based Ligands for $\mathrm{Ln}^{3+}$ Ions 
Table 2

Stability Constants of the Intermediate Chelates $\mathrm{H}_{2} \mathrm{LnL}^{+}$for a Variety of DOTA-Type Ligands $(\mathrm{I}=1.0 \mathrm{M}$ $\mathrm{KCl}, 25^{\circ} \mathrm{C}$ )

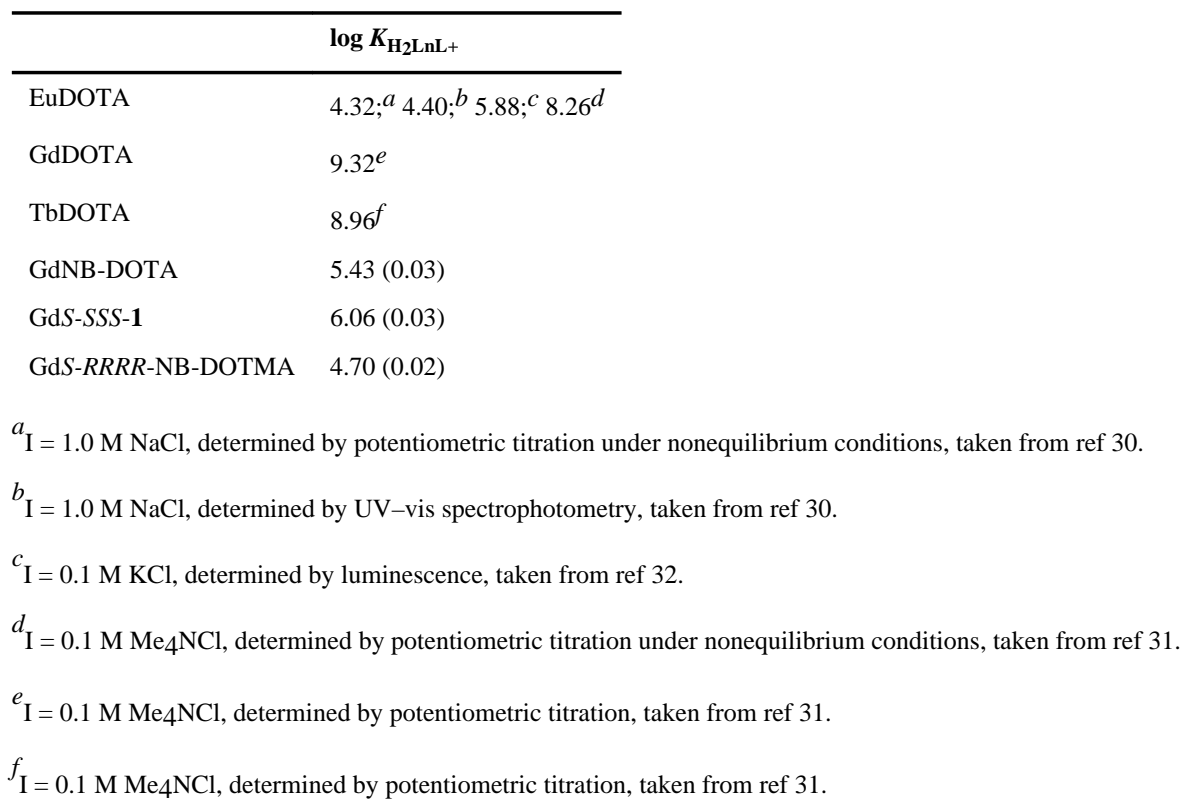


Table 3

Summary of the Kinetics of Formation of $\mathrm{Gd}^{3+}$ Chelates $\left(\mathrm{I}=1.0 \mathrm{M} \mathrm{KCl}, 25^{\circ} \mathrm{C}\right)$

\begin{tabular}{lll}
\hline & $\boldsymbol{k}_{\mathbf{H}_{\mathbf{2}} \mathbf{O}}\left(\mathbf{s}^{-\mathbf{1}}\right)$ & $\boldsymbol{k}_{\mathbf{O H}^{-}}\left(\mathbf{M}^{-\mathbf{1}} \mathbf{s}^{-\mathbf{1}}\right)$ \\
\hline DOTA $^{a}$ & not detected & $7.5 \times 10^{6}$ \\
NB-DOTA & $(9.1 \pm 1.1) \times 10^{-5}$ & $(1.6 \pm 0.8) \times 10^{6}$ \\
S-SSS-1 & $(1.4 \pm 0.2) \times 10^{-4}$ & $(6.8 \pm 0.4) \times 10^{3}$ \\
S-RRRR-NB-DOTMA & $(-5.0 \pm 0.8) \times 10^{-5}$ & $(6.4 \pm 0.3) \times 10^{4}$ \\
${ }^{a}$ Data published in ref 33 was re-examined according to eq 6.
\end{tabular}




\section{Table 4}

\section{Crystallographic Data for $\mathrm{H}_{4}$ DOTMA $\bullet 2 \mathrm{HCl} \bullet 3 \mathrm{H}_{2} \mathrm{O}$}

\begin{tabular}{|c|c|}
\hline empirical formula & $\mathrm{C}_{20} \mathrm{H}_{44} \mathrm{Cl}_{2} \mathrm{~N}_{4} \mathrm{O}_{11}$ \\
\hline formula weight & 587.49 \\
\hline temperature $(\mathrm{K})$ & $173(2)$ \\
\hline wavelength $(\AA)$ & 0.71073 \\
\hline crystal system & orthorhombic \\
\hline space group & $P 2_{1} 2_{1} 2_{1}$ \\
\hline$a(\AA)$ & $9.5934(7)$ \\
\hline$b(\AA)$ & $15.8093(12)$ \\
\hline$c(\AA)$ & $18.7282(14)$ \\
\hline$\alpha$ & $90^{\circ}$ \\
\hline$\beta$ & $90^{\circ}$ \\
\hline$\gamma$ & $90^{\circ}$ \\
\hline volume $\left(\AA^{3}\right)$ & $2840.4(4)$ \\
\hline$Z$ & 4 \\
\hline density (calculated) $\left(\mathrm{Mg} / \mathrm{m}^{3}\right)$ & 1.374 \\
\hline absorption coefficient $\left(\mathrm{mm}^{-1}\right)$ & 0.289 \\
\hline$F(000)$ & 1256 \\
\hline crystal color, morphology & colorless, block \\
\hline crystal size $\left(\mathrm{mm}^{3}\right)$ & $0.20 \times 0.10 \times 0.10$ \\
\hline$\theta$ range for data collection & 1.69 to $25.05^{\circ}$ \\
\hline index ranges & $-11 \leq h \leq 11,-18 \leq k \leq 18,-22 \leq l \leq 22$ \\
\hline reflections collected & 24064 \\
\hline independent reflections & $5022[R($ int $)=0.0545]$ \\
\hline observed reflections & 4221 \\
\hline completeness to $\theta=25.05^{\circ}$ & $99.9 \%$ \\
\hline absorption correction & multiscan \\
\hline max. and min transmission & 0.9717 and 0.9445 \\
\hline refinement method & full-matrix least-squares on $F^{2}$ \\
\hline data/restraints/parameters & $5022 / 0 / 342$ \\
\hline goodness-of-fit on $F^{2}$ & 1.011 \\
\hline final $R$ indices $[I>2 \sigma(I)]$ & $R 1=0.0441, w R 2=0.0976$ \\
\hline$R$ indices (all data) & $R 1=0.0607, w R 2=0.1085$ \\
\hline absolute structure parameter & $-0.13(8)$ \\
\hline largest diff. peak and hole & 0.872 and $-0.476{\mathrm{e} \AA^{-3}}^{-3}$ \\
\hline
\end{tabular}


Table 5

Selected Distance and Angles from the Crystal Structures of $\mathrm{H}_{4}$ DOTMA $\bullet 2 \mathrm{HCl} \cdot 3 \mathrm{H}_{2} \mathrm{O}$ and $\mathrm{H}_{4} \mathrm{DOTA} \cdot 2 \mathrm{HCl}$ - $5 \mathrm{H}_{2} \mathrm{O}^{11}$

\begin{tabular}{lllll}
\hline parameter & H6DOMA & parameter & H6DOTA \\
\hline \multicolumn{5}{c}{ Angles [deg] } \\
N1-C-C-N2 & -49.05 & N1-C-C-N2 & -53.57 \\
N2-C-C-N3 & -69.84 & N2-C-C-N3 & -59.76 \\
N3-C-C-N4 & -49.47 & N3-C-C-N4 & -57.09 \\
N4-C-C-N1 & -68.83 & N4-C-C-N1 & -60.39 \\
N1-C-C-O2 & 10.41 & N1-C-C-O4 & 4.19 \\
N2-C-C-O3 & -1.53 & N2-C-C-O1 & 6.42 \\
N3-C-C-O5 & 23.29 & N3-C-C-O6 & 7.35 \\
N4-C-C-O7 & 21.20 & N4-C-C-O7 & 10.79 \\
N1-N2-N3 & 80.41 & N1-N2-N3 & 86.17 \\
N2-N3-N4 & 99.62 & N2-N3-N4 & 94.69 \\
N3-N4-N1 & 79.90 & N3-N4-N1 & 85.71 \\
N4-N1-N2 & 99.87 & N4-N1-N2 & 93.43 \\
O2-O3-O5 & 131.74 & O1-O6-O7 & 82.26 \\
O3-O5-O7 & 51.58 & O6-O7-O4 & 93.71 \\
O5-O7-O2 & 112.50 & O7-O4-O1 & 84.98 \\
O7-O2-O3 & 64.04 & O4-O1-O6 & 98.92 \\
N $4-O{ }_{4}$ & 2.384 & & \\
\hline & & & 2.507 \\
\hline
\end{tabular}




\section{Table 6}

Calculated Energy Differences (MM+) of Ligand Conformations Resulting from the Introduction of a Benzyl Substituent into the Crystal Structure of $\mathrm{H}_{6}$ DOTMA and the Lowest Energy Conformation so Obtained ${ }^{a}$

\begin{tabular}{lllr}
\hline & & \multicolumn{2}{c}{$\Delta E(\mathbf{k c a l} / \mathbf{A}$ mol $)$} \\
\cline { 3 - 4 } carbon & position & H. $_{\mathbf{6}} \mathbf{D O T M A}$ & H. $_{2}$ DOTMA \\
\hline $\mathrm{C} 1$ & eq. corner & +10.0 & +0.12 \\
$\mathrm{C} 2$ & eq. side & +10.8 & +4.86 \\
$\mathrm{C} 3$ & eq. corner & 0.00 & +0.36 \\
$\mathrm{C} 4$ & eq. side & +14.9 & +7.69 \\
$\mathrm{C} 5$ & eq. corner & +7.70 & +0.90 \\
$\mathrm{C} 6$ & eq. side & +13.1 & +4.81 \\
$\mathrm{C} 7$ & eq. corner & +0.80 & 0.00 \\
$\mathrm{C} 8$ & eq. side & +12.6 & +6.36
\end{tabular}

${ }^{a}$ In the case of $\mathrm{H}_{6}$ DOTMA the ligand structure was constrained and only the energy of the benzylic substituent was minimized; for $\mathrm{H}_{2}$ DOTMA no part of the ligand structure was constrained during the calculations. 


\section{Table 7}

Stability Constants $\left(\log K_{\mathrm{ML}}\right)$ of the $\mathrm{Ce}^{3+}, \mathrm{Gd}^{3+}, \mathrm{Yb}^{3+}$, and $\mathrm{Lu}^{3+}$ Chelates of $S$-RRRR-NB-DOTMA (SAP), $S$ $S S S-1$ (TSAP), DOTA, and NB-DOTA $\left(\mathrm{I}=1.0 \mathrm{M} \mathrm{KCl,} 25^{\circ} \mathrm{C}\right)$

\begin{tabular}{lllll}
\hline Ln $^{3+}$ & S-RRRR-NB-DOTMA & S-SSS-1 & DOTA $^{\boldsymbol{a}}$ & NB-DOTA $^{\boldsymbol{b}}$ \\
\hline $\mathrm{Ce}^{3+}$ & $19.79(0.06)$ & $24.04(0.07)$ & 23.4 & \\
$\mathrm{Gd}^{3+}$ & $23.86(0.07)$ & $21.53(0.11)$ & 24.7 & 24.2 \\
$\mathrm{Yb}^{3+}$ & $24.12(0.09)$ & $21.91(0.08)$ & 25.0 & \\
$\mathrm{Lu}^{3+}$ & & & & 24.5 \\
$\mathrm{pGd}$ & 19.51 & 16.02 & 19.01 & 19.88 \\
${ }^{\text {From ref 25. }}$ & & & \\
$b_{\text {From ref 21, data recorded with I }=1.0 \mathrm{M} \mathrm{NMe}_{4} \mathrm{Cl} .}$
\end{tabular}

